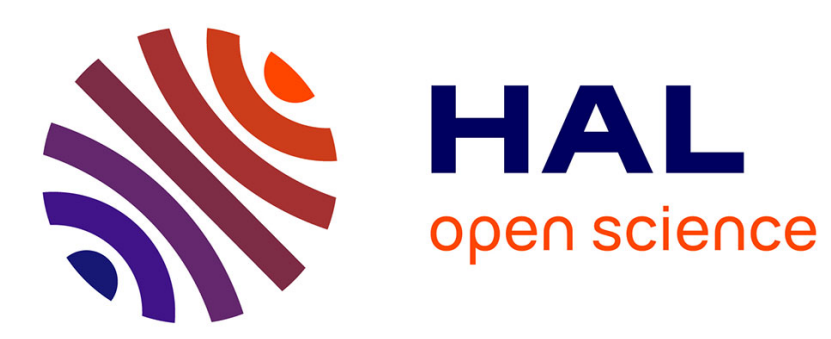

\title{
Finite element analysis of free-edge stresses in composite laminates under mechanical an thermal loading
}

Viet-Tung Nguyen, Jean-François Caron

\section{To cite this version:}

Viet-Tung Nguyen, Jean-François Caron. Finite element analysis of free-edge stresses in composite laminates under mechanical an thermal loading. Composites Science and Technology, 2009, 69 (1), pp.40. 10.1016/j.compscitech.2007.10.055 . hal-00563497

\section{HAL Id: hal-00563497 \\ https://hal.science/hal-00563497}

Submitted on 6 Feb 2011

HAL is a multi-disciplinary open access archive for the deposit and dissemination of scientific research documents, whether they are published or not. The documents may come from teaching and research institutions in France or abroad, or from public or private research centers.
L'archive ouverte pluridisciplinaire HAL, est destinée au dépôt et à la diffusion de documents scientifiques de niveau recherche, publiés ou non, émanant des établissements d'enseignement et de recherche français ou étrangers, des laboratoires publics ou privés. 


\section{Accepted Manuscript}

Finite element analysis of free-edge stresses in composite laminates under mechanical an thermal loading

Viet-Tung Nguyen, Jean-Francois Caron

PII: S0266-3538(07)00439-3

DOI: 10.1016/j.compscitech.2007.10.055

Reference: CSTE 3888

To appear in:

$$
\text { Composites Science and Technology }
$$

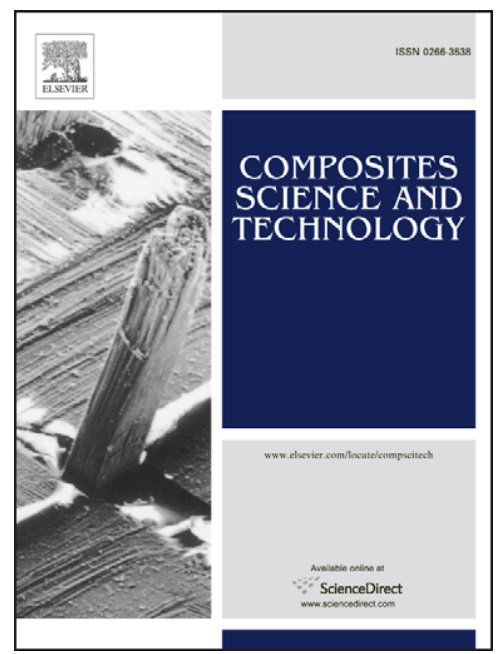

Received Date: $\quad 31$ March 2006

Accepted Date: $\quad 11$ October 2007

Please cite this article as: Nguyen, V-T., Caron, J-F., Finite element analysis of free-edge stresses in composite laminates under mechanical an thermal loading, Composites Science and Technology (2007), doi: 10.1016/ j.compscitech.2007.10.055

This is a PDF file of an unedited manuscript that has been accepted for publication. As a service to our customers we are providing this early version of the manuscript. The manuscript will undergo copyediting, typesetting, and review of the resulting proof before it is published in its final form. Please note that during the production process errors may be discovered which could affect the content, and all legal disclaimers that apply to the journal pertain. 


\title{
Finite element analysis of free-edge stresses in composite laminates under mechanical an thermal loading
}

\author{
Viet-Tung Nguyen ${ }^{\mathrm{a}}$, Jean-Francois Caron ${ }^{\mathrm{b}, *}$ \\ ${ }^{a} M S C / C C G R$ - Laboratoire Centrale des Ponts et Chaussée, route de Bouaye, \\ Bougenais cedex, France \\ ${ }^{\mathrm{b}}$ LAMI(ENPC/LCPC, Institut Navier), 6-8 avenue Blaise Pascal, Cité Descartes, \\ Champs-sur-Marne, 77455 MARNE-LA-VALLEE, Cedex 2, France
}

\begin{abstract}
In this paper, a multi-particle finite element [1] is applied for general laminated and is shown to be capable of simultaneously predicting global and local responses. The analysis of free-edge stresses of composite laminates subjected to mechanical and thermal loads is performed using this $\mathbb{C}^{o}$ eight-node layer-wise finite element after a classical bending validation. Laminates with finite dimensions are considered and three-dimensional out-of-plane stresses in the interior and near the free edges are evaluated. The results obtained with this finite element modelling are compared with those available in the literature. The present calculation provides accurate stresses and can be utilised as and operational tool to predict interlaminar stresses under the loads of mechanical and thermal combined.
\end{abstract}

Key words: Free edge; Layer-wise; finite element; Laminates; Interfacial stresses

Preprint submitted to Elsevier Science

31 March 2006 


\section{Introduction}

The recent widespread use of laminated composites in various industrial fields necessitates analysis tools which are capable of predicting their mechanical behaviour more accurately an efficiently.

For laminated composites, it is well known that at the free edges interlaminar stresses arise from the mismatch of elastic properties between layers. Hence, the stress distribution in the vicinity of the free edges is in three dimensional (3D) state even though the laminates are only subjected to in-plane loading. The interlaminar stresses are important because they have a marked effect on the failure strengths of composite laminates. Accurate determination of interlaminar stresses near the free edge is therefore crucial to correctly describe the laminate behaviour and to prevent its early failure, notably the delamination onset.

Classical single layer theories are not able to calculate these out-of-plane stresses, notably in presence of free edges. Therefore various approaches such as finite difference [2,3], 3D finite element [4-7], closed-form analytical approach using mixed formulation and stress based methods [8-10], boundary layer theories [11-14] and layer-wise theories [15-17] have been used to calculate interlaminar stresses near free edges. A complete discussion of the literature on the interlaminar stress analysis can be found in [18].

Finite differences, which are the oldest in the field, have been used in: $[2,3]$ to solve the two-dimensional governing elasticity equations to determine the

* Corresponding author. Tel.: +33-1-6415-3723

Email address: caron@lami.enpc.fr (Jean-Francois Caron ). 
interlaminar stresses in a long symmetric laminate under uniform axial strain. Although 3D FE method [4-7] is the most universal method that can be applied to general stacking sequence and boundary conditions, it is quite computational expensive and presents difficulties for convergence in the vicinity of free edges (see [19]). Consequently, some semi-analytical approaches combining the traditional FE method with certain analytical techniques have been proposed. A state space FE method that combines the conventional FE approximation and the recursive formulation of state space equation: state space formulation is introduced to solve for through-thickness stress distributions, while the traditional FE is used to approximate in-plane variations of the state variables in $[20-22]$.

In order to avoid these somewhat cumbersome 3D FE methods, several approximate analytical methods have been equally proposed. Some pioneering works involve the perturbation technique by Hsu and Herakovich [23], the boundary layer theory by Tang and Levy [11], and the approximate elasticity solution by Pipes and Pagano [24]. Mixed variational principle has been used along with stress assumption by Pagano [9]. Wang and Choi [12,13] have presented a formulation of Lekhnitskii's stress function based on complex variables. Kassapoglou and Lagace [10] studied the edge effect using the principle of minimum complementary energy and the force balance method. A large amount of development devoted to free-edge stresses analysis have been formulated based on this procedure: using stress functions and principle of complementary energy $[14,25-27]$

Another alternative method to study the edge effect involves models based on layer-wise theory [15-17]. Unlike the single layer theories, the layer-wise theories assume separate field expansions within each layer and thereby pro- 
vide a more kinematically correct representation of the strain and stress field in each discrete layer. However relatively less attention has been addressed to the development of layer-wise based FE for interlaminar free-edge stresses analysis. Most of layer-wise FEs developed for free edge analysis [28-30] are based on the hybrid stress concept using the variational principle of Pian [31]. Recently, Kimpara and coauthor have developed a layer-wise FE based on assumed higher order displacement in each ply [32]. Imaginary springs attached at the interlayers have been used to ensure interfacial continuity.

Based on a typical layer-wise model, called the M4-5n (Multi-particle Model of $M$ ultilayered $M$ aterials with 5 kinematic fields per layer for an $n$-layer laminate $[19,33-35])$ a new layer-wise finite element has been developed in [1]. The potential of this finite element for the analysis of free-edge composites under mechanical loading has been revealed. In the present work, detail investigation of free-edge stress fields under mechanical and thermal loadings is performed with this finite element. Firstly, a rectangular simply supported laminate subjected to a sinusoidal transverse load is examined using this multi-particle FE and the results will be compared with Pagano's three-dimensional elasticity solution [36]. Agreement between the results will show the validity and accuracy of the proposed finite element. Then, after the reliability of the FE model would successfully be validated, straight free edge problem will be considered in comparison with existed solution in the literature. Discussion of solution's sensibility again the number of modelled sub-layers is also presented. 
2 Governing equations of the $M 4-5 n$ model for general composite laminates

\subsection{Laminated plate geometry, preliminaries}

Consider a composite laminated plate (Fig. 1) consisting of $n$ linearly elastic orthotropic layers, each of them exhibiting individual mechanical properties. It is assumed that the layers are perfectly bonded together so that slip between two adjacent layers may not occur. The thickness of each layer $k(k=1, n)$ is denoted $e_{k}=h_{k}^{+}-h_{k}^{-}$, where $h_{k}^{-}, h_{k}^{+}$are the bottom and the top $z$ coordinates of the layer, respectively. The occupied volume is then $\Omega=\omega \times\left[h_{1}^{-}, h_{n}^{+}\right]$. The interface between layer $j$ and $j+1$ is denoted $\Gamma_{j, j+1}(1 \leq j \leq n-1)$.

For the sake of convenience, throughout this paper the indicial notations are used. Greek indices $\alpha, \beta, \gamma$ and $\delta$ indicate the components on the $(x, y)$ plane and and run over the range 1,2. Latin indices $o, p, q$ and $r$ indicate the components in the $(x, y, z)$ space and run over the range 1,2,3. Superscript $k$ attached on any quantity identifies affiliation to the $k$ layer. Bold face characters are used to represent tensors, matrices and vectors. 


\subsection{Generalised displacements}

The in-plane displacement and rotation fields of layer $k$ of the $M 4-5 n$ model are defined in the following way:

$$
\begin{aligned}
& U_{\alpha}^{k}(x, y)=\frac{1}{e^{k}} \int_{h_{k}^{-}}^{h_{k}^{+}} U_{\alpha}(x, y, z) d z \\
& \phi_{\alpha}^{k}(x, y)=\frac{12}{e^{k^{2}}} \int_{h_{k}^{-}}^{h_{k}^{+}} \frac{z-\bar{h}_{k}}{e^{k}} U_{\alpha}(x, y, z) d z
\end{aligned}
$$

where $\bar{h}_{k}$ are the mid-plane $z$ coordinate of the layer $k$.

The transverse displacement of layer $k, U_{3}^{k}$ is defined such that

$$
U_{3}^{k}(x, y)=\frac{1}{e^{k}} \int_{h_{k}^{-}}^{h_{k}^{+}} U_{3}(x, y, z) d z
$$

Thus each layer presents $5 n$ kinematic fields. The multi-layered plate (3D object) becomes a superposition of $n$ Reissner plates (2D object). 


\subsection{The strain-displacement equations}

The generalised strains are deduced from the generalised displacements as follows (see $[19,37]$ for more details):

$$
\begin{aligned}
& \varepsilon_{\alpha \beta}^{k}=\frac{1}{2}\left(U_{\alpha, \beta}^{k}+U_{\beta, \alpha}^{k}\right), \\
& \chi_{\alpha \beta}^{k}=\frac{1}{2}\left(\phi_{\alpha, \beta}^{k}+\phi_{\beta, \alpha}^{k}\right), \\
& \gamma_{\alpha}^{k}=\phi_{\alpha}^{k}+U_{3, \alpha}^{k}, \\
& D_{\alpha}^{j, j+1}=U_{\alpha}^{j+1}-U_{\alpha}^{j}-\frac{e^{j}}{2} \phi_{\alpha}^{j}-\frac{e^{j+1}}{2} \phi_{\alpha}^{j+1}, \\
& D_{\nu}^{j, j+1}=U_{3}^{j+1}-U_{3}^{j} .
\end{aligned}
$$

In each layer $k$, one can find the conventional membranar strain $\varepsilon_{\alpha \beta}^{k}$, bending curvatures $\chi_{\alpha \beta}^{k}$ and shear strains $\gamma_{\alpha}^{k}$. At each interface $\Gamma_{j, j+1}$, the interlaminar strains $D_{\alpha}^{j, j+1}, D_{\nu}^{j, j+1}$ are defined associated to interlaminar transverse shear stresses $\sigma_{\alpha 3}\left(x, y, h_{j}^{+}\right)$and normal stress $\sigma_{33}\left(x, y, h_{j}^{+}\right)$, respectively.

2.4 Generalised stresses and equilibrium equations

In layer $k(1 \leq k \leq n)$, the generalised in-plane stress resultants $\mathbf{N}^{k}$, the generalised in-plane moment resultants $\mathbf{M}^{k}$ and the generalised out-of-plane 
shear stress resultants $\mathbf{Q}^{k}$ are defined as follows:

$$
\begin{aligned}
& N_{\alpha \beta}^{k}(x, y)=\int_{h_{k}^{-}}^{h_{k}^{+}} \sigma_{\alpha \beta}(x, y, z) d z, \\
& M_{\alpha \beta}^{k}(x, y)=\int_{h_{k}^{-}}^{h_{k}^{+}}\left(z-\bar{h}_{k}\right) \sigma_{\alpha \beta}(x, y, z) d z, \\
& Q_{\alpha}^{k}(x, y)=\int_{h_{k}^{-}}^{h_{k}^{+}} \sigma_{\alpha 3}(x, y, z) d z .
\end{aligned}
$$

The interlaminar shear and normal stresses at interface $j, j+1 \quad(1 \leq j \leq n-1)$ are defined as

$$
\begin{aligned}
& \tau_{\alpha}^{j, j+1}(x, y)=\sigma_{\alpha 3}\left(x, y, h_{j}^{+}\right), \\
& \nu^{j, j+1}(x, y)=\sigma_{33}\left(x, y, h_{j}^{+}\right) .
\end{aligned}
$$

The equilibrium equations of the $M 4-5 n$ model can be written as

$$
\begin{aligned}
& N_{\alpha \beta, \beta}^{k}+\left(\tau_{\alpha}^{k, k+1}-\tau_{\alpha}^{k-1, k}\right)=0, \\
& Q_{\beta, \beta}^{k}+\left(\nu^{k, k+1}-\nu^{k-1, k}\right)=0, \\
& M_{\alpha \beta, \beta}^{k}+\frac{e^{k}}{2}\left(\tau_{\alpha}^{k, k+1}+\tau_{\alpha}^{k-1, k}\right)-Q_{\alpha}^{k}=0 .
\end{aligned}
$$

\subsection{Generalised constitutive equations}

The $M 4-5 n$ generalised constitutive equations are obtained in compliance terms, related to: 
- The membranar stress resultants in layer $k(1 \leq k \leq n)$

$$
\left(\begin{array}{c}
\varepsilon_{11}^{k} \\
\varepsilon_{22}^{k} \\
2 \varepsilon_{12}^{k}
\end{array}\right)=\frac{1}{e^{k}} \boldsymbol{S}^{k}\left(\begin{array}{c}
N_{11}^{k} \\
N_{22}^{k} \\
N_{12}^{k}
\end{array}\right),
$$

where the second-order tensor $\boldsymbol{S}^{k}$ represents the in-plane compliances of layer $k$ defined by $S_{\alpha \beta}^{k}=S_{\alpha \alpha \beta \beta}(z), S_{16}^{k}=S_{61}^{k}=2 S_{1112}(z), S_{26}^{k}=S_{62}^{k}=$ $2 S_{2212}(z), S_{66}^{k}=4 S_{1212}(z)$

- the in-plane moment resultants in layer $k(1 \leq k \leq n)$

$$
\left(\begin{array}{c}
\chi_{11}^{k} \\
\chi_{22}^{k} \\
2 \chi_{12}^{k}
\end{array}\right)=\frac{12}{e^{k^{3}}} \boldsymbol{S}^{k}\left(\begin{array}{c}
M_{11}^{k} \\
M_{22}^{k} \\
M_{12}^{k}
\end{array}\right),
$$

- the out-of-plane shear stress resultants in layer $k(1 \leq k \leq n)$

$$
\left(\begin{array}{c}
\gamma_{1}^{k} \\
\gamma_{2}^{k}
\end{array}\right)=\frac{6}{5 e^{k}} \boldsymbol{S}_{\boldsymbol{Q}}^{k}\left(\begin{array}{l}
Q_{1}^{k} \\
Q_{2}^{k}
\end{array}\right)-\frac{1}{10} \boldsymbol{S}_{\boldsymbol{Q}}^{k}\left(\begin{array}{c}
\tau_{1}^{k-1, k}+\tau_{1}^{k, k+1} \\
\tau_{2}^{k-1, k}+\tau_{2}^{k, k+1}
\end{array}\right)
$$

where the second-order tensor $\boldsymbol{S}_{\boldsymbol{Q}}^{k}$ represents the shearing compliances of layer $k$ defined by $S_{Q \alpha \beta}^{k}=4 S_{\alpha 3 \beta 3}(z)$; 
- the transverse shear stresses at interface $\Gamma_{j, j+1}(1 \leq j \leq n-1)$

$$
\begin{aligned}
& \left(\begin{array}{c}
D_{1}^{j, j+1} \\
D_{2}^{j, j+1}
\end{array}\right)=-\frac{1}{10} \boldsymbol{S}_{\boldsymbol{Q}}^{j}\left(\begin{array}{l}
Q_{1}^{j} \\
Q_{2}^{j}
\end{array}\right)-\frac{1}{10} \boldsymbol{S}_{\boldsymbol{Q}}^{j+1}\left(\begin{array}{l}
Q_{1}^{j+1} \\
Q_{2}^{j+1}
\end{array}\right) \\
& +\frac{2}{15}\left(e^{j} \boldsymbol{S}_{\boldsymbol{Q}}^{j}+e^{j+1} \boldsymbol{S}_{\boldsymbol{Q}}^{j+1}\right)\left(\begin{array}{c}
\tau_{1}^{j, j+1} \\
\tau_{2}^{j, j+1}
\end{array}\right) \\
& -\frac{e^{j}}{30} \boldsymbol{S}_{\boldsymbol{Q}}^{j}\left(\begin{array}{c}
\tau_{1}^{j-1, j} \\
\tau_{2}^{j-1, j}
\end{array}\right)-\frac{e^{j+1}}{30} \boldsymbol{S}_{\boldsymbol{Q}}^{j+1}\left(\begin{array}{c}
\tau_{1}^{j+1, j+2} \\
\tau_{2}^{j+1, j+2}
\end{array}\right)
\end{aligned}
$$

- the normal stresses at interface $\Gamma_{j, j+1}(1 \leq j \leq n-1)$

$$
\begin{aligned}
D_{\nu}^{j, j+1}= & \frac{9}{70} e^{j} S_{\nu}^{j} \nu^{j-1, j}+\frac{13}{35}\left(e^{j} S_{\nu}^{j}+e^{j+1} S_{\nu}^{j+1}\right) \\
& +\frac{9}{70} e^{j+1} S_{\nu}^{j+1} \nu^{j+1, j+2}
\end{aligned}
$$

where the scalar $S_{\nu}^{j}$ denotes the normal compliance of layer $j$ defined by $S_{\nu}^{j}=S_{33}(z)=S_{3333}(z)$

\section{Finite element modelling of $M 4-5 n$ equations}

\subsection{Finite element discretisation}

The standard finite element formulation with $\mathbb{C}^{o}$ continuous plate element has been used in this investigation. In this approach, the entire domain is 
subdivided in $N E$ number of sub-domains or elements such that

$$
\Pi(\delta)=\sum_{e l=1}^{N E} \Pi^{e}(\delta)
$$

where $\Pi$ and $\Pi^{e}$ are the total potential of the system and the element, respectively. For a $n$-layer plate, the $5 n$ vector of unknown nodal displacement variables are defined as

$$
\boldsymbol{\delta}=\left\{U^{1} V^{1} W^{1} \phi_{x}{ }^{1} \phi_{y}{ }^{1}, \cdots, U^{n} V^{n} W^{n} \phi_{x}{ }^{n} \phi_{y}{ }^{n}\right\}^{T}
$$

where the conventional engineering notations $U=U_{1}, V=U_{2}, W=U_{3}, \phi_{x}=\phi_{1}$ and $\phi_{y}=\phi_{2}$ are used. Note that to study the through-the-thickness stresses distribution, each physical layer can be subdivided in to a large number of numerical (or mathematical) layers by introducing more interfaces and therefore more unknown displacement variables.

In this study, eight-node two-dimensional shape functions $N_{i}(i=1,8)$ are adopted for interpolating both the geometry and generalised displacement such that:

$$
\begin{aligned}
(x, y) & =\sum_{i=1}^{8} N_{i}\left(x_{i}, y_{i}\right), \\
\boldsymbol{\delta} & =\sum_{i=1}^{8} \mathbb{N}_{i} \boldsymbol{\delta}_{i},
\end{aligned}
$$

where $x_{i}, y_{i}$ and $\boldsymbol{\delta}_{i}$ are the nodal values. The interpolation functions matrix for the node $i$ are $\mathbb{N}_{i}=N_{i} \mathbf{I}_{5 n}$. The explicit expressions of $N_{i}$ can be found in $[38]$.

The $(11 n-3)$ complete generalised strain vector $\boldsymbol{\epsilon}$ is defined as follows:

$$
\boldsymbol{\epsilon}=\left\{\boldsymbol{\epsilon}^{c}, \boldsymbol{\epsilon}^{\nu}, \boldsymbol{\epsilon}^{Q}\right\}^{T}
$$


where

$$
\boldsymbol{\epsilon}^{c}=\left\{\varepsilon_{x x}^{1} \varepsilon_{y y}^{1} 2 \varepsilon_{x y}^{1} \chi_{x x}^{1} \chi_{y y}^{1} \chi_{x y}^{1} \ldots \varepsilon_{x x}^{n} \varepsilon_{y y}^{n} 2 \varepsilon_{x y}^{n} \chi_{x x}^{n} \chi_{y y}^{n} \chi_{x y}^{n}\right\}^{T}
$$

is the $6 n$ membranar strain vector,

$$
\boldsymbol{\epsilon}^{\nu}=\left\{D_{3}^{1,2} D_{3}^{2,3} \ldots D_{3}^{n-1, n}\right\}^{T}
$$

is the $(n-1)$ normal strain vector and

$$
\boldsymbol{\epsilon}^{Q}=\left\{\gamma_{x}^{1} \gamma_{y}^{1} D_{x}^{1,2} D_{y}^{1,2} \gamma_{x}^{2} \gamma_{y}^{2} \ldots \gamma_{x}^{n-1} \gamma_{y}^{n-1} D_{x}^{n-1, n} D_{y}^{n-1, n} \gamma_{x}^{n} \gamma_{y}^{n}\right\}^{T}
$$

is the $(4 n-2)$ shear strain vector.

The associated generalised stress vector can be written as follows:

$$
\boldsymbol{\sigma}=\left\{\boldsymbol{\sigma}^{c}, \boldsymbol{\sigma}^{\nu}, \boldsymbol{\sigma}^{Q}\right\}^{T}
$$

where

$$
\begin{aligned}
\boldsymbol{\sigma}^{c} & =\left\{N_{x x}^{1} N_{y y}^{1} N_{x y}^{1} M_{x x}^{1} M_{y y}^{1} M_{x y}^{1} \ldots N_{x x}^{n} N_{y y}^{n} N_{x y}^{n} M_{x x}^{n} M_{y y}^{n} M_{x y}^{n}\right\}^{T} \\
\boldsymbol{\sigma}^{\nu} & =\left\{\nu^{1,2} \nu^{2,3} \ldots \nu^{n-1, n}\right\}^{T} \\
\boldsymbol{\sigma}^{Q} & =\left\{Q_{x}^{1} Q_{y}^{1} \tau_{x}^{1,2} \tau_{y}^{1,2} Q_{x}^{2} Q_{y}^{2} \ldots Q_{x}^{n-1} Q_{y}^{n-1} \tau_{x}^{n-1, n} \tau_{y}^{n-1, n} Q_{x}^{n} Q_{y}^{n}\right\}^{T}
\end{aligned}
$$

The membranar, normal ans shear strains $\boldsymbol{\epsilon}^{c}, \boldsymbol{\epsilon}^{\nu}, \boldsymbol{\epsilon}^{Q}$ can be written in terms of the nodal displacements $\boldsymbol{\delta}$ by referring to Eq. (3). With the generalised displacement vector $\boldsymbol{\delta}$ known at all points within the element, the generalised strain vectors at any point are determined with the aid of Eq. (14), as follows:

$$
\boldsymbol{\epsilon}=\sum_{i=1}^{8} \mathbb{B}_{i} \boldsymbol{\delta}_{i}=\left[\mathbb{B}_{1}, \ldots, \mathbb{B}_{8}\right] \boldsymbol{\delta}
$$

The strain energy stored in the element can be computed using stress-strain 
relation equations $(7)-(11)$ :

$$
\pi^{e}=\frac{1}{2} \int_{\omega} \boldsymbol{\delta}^{T} \mathbb{B}^{T} \mathbf{D} \mathbb{B} \boldsymbol{\delta} d \omega=\frac{1}{2} \boldsymbol{\delta}^{T} \mathbf{K}^{e} \boldsymbol{\delta}
$$

Detail expression of operator matrix $\mathbb{B}$ and elasticity matrix $\mathbf{D}$ can be found in [1]. By assembling the element stiffness matrices and taking into account the boundary conditions, the nodal d.o.f. can be solved.

\subsection{Layer-wise temperature variation}

A layer-wise uniform temperature variation can be taken in to account using the procedure proposed in [35]. The tensor of inelastic strain due to a uniform temperature variation $T^{i}$ in the $k$ layer is identified as

$$
\varepsilon^{k a}(\underline{x})=T^{k}\left(\alpha_{L}^{k} \underline{e_{L}} \otimes \underline{e_{L}}+\alpha_{T}^{k} \underline{e_{T}} \otimes \underline{e_{T}}+\alpha_{N}^{k} \underline{e_{z}} \otimes \underline{e_{z}}\right)
$$

where $\alpha_{L}^{k}, \alpha_{T}^{k}$ et $\alpha_{N}^{k}$ represent thermal coefficient in material direction.

In the global $x, y, z$ coordinate this inelastic strain tensor can be written as

$$
\varepsilon^{k a}(\underline{x})=T^{k}\left(\alpha_{11}^{k} \underline{e_{x}} \otimes \underline{e_{x}}+\alpha_{22}^{k} \underline{e_{y}} \otimes \underline{e_{y}}+\alpha_{12}^{k}\left(\underline{e_{x}} \otimes \underline{e_{y}}+\underline{e_{y}} \otimes \underline{e_{x}}\right)+\alpha_{33}^{k} \underline{e_{z}} \otimes \underline{e_{z}}\right)
$$

where

$$
\begin{aligned}
\alpha_{11}^{k} & =\cos ^{2} \theta_{k} \alpha_{L}^{k}+\sin ^{2} \theta_{k} \alpha_{T}^{k} \\
\alpha_{22}^{k} & =\sin ^{2} \theta_{k} \alpha_{L}^{k}+\cos ^{2} \theta_{k} \alpha_{T}^{k} \\
\alpha_{12}^{k} & =\cos \theta_{k} \sin \theta_{k}\left(\alpha_{L}^{k}-\alpha_{T}^{k}\right) \\
\alpha_{33}^{k} & =\alpha_{N}^{k} .
\end{aligned}
$$

with $\theta_{k}$ is the orientation of the $i$ layer. 
Finally, according to [35] the inelastic strain can be expressed as

$$
\begin{aligned}
\varepsilon_{\alpha \beta}^{k a}(x, y) & =\alpha_{\alpha \beta}^{k} T^{i} \\
\chi_{\alpha \beta}^{k a}(x, y) & =0 \\
\gamma_{\alpha}^{k a}(x, y) & =0 \\
D_{\alpha}^{j, j+1 a}(x, y) & =0 \\
D_{\nu}^{j, j+1 a}(x, y) & =\alpha_{33}^{j} T^{j} \frac{e^{j}}{2}+\alpha_{33}^{j+1} T^{j+1} \frac{e^{j+1}}{2}
\end{aligned}
$$

The inelastic strain vector according to the multi-particle finite element formulation are:

$$
\boldsymbol{\epsilon}^{a}=\left\{\boldsymbol{\epsilon}^{c a}, \boldsymbol{\epsilon}^{\nu a}, \boldsymbol{\epsilon}^{Q a}\right\}^{T}
$$

with

$$
\begin{aligned}
& \boldsymbol{\epsilon}^{c a}=\{\underbrace{\varepsilon_{x x}^{1 a} \varepsilon_{y y}^{1 a} 2 \varepsilon_{x y}^{1 a} 000, \ldots, \varepsilon_{x x}^{n a} \varepsilon_{y y}^{n a} 2 \varepsilon_{x y}^{n a} 000}_{6 n}\}^{T} \\
& \boldsymbol{\epsilon}^{\nu a}=\{\underbrace{D_{\nu}^{1,2 a} D_{\nu}^{2,3 a} \ldots D_{\nu}^{n-1, n a}}_{n-1}\}^{T} \\
& \boldsymbol{\epsilon}^{Q a}=\{\underbrace{\begin{array}{lllllllllll}
0 & 0 & 0 & 0 & 0 & 0, \ldots, 0 & 0 & 0 & 0 & 0 & 0
\end{array}}_{4 n-2}\}^{T}
\end{aligned}
$$

\section{Numerical results}

In this section, the developed finite element is initially applied to study the bidirectional bending problem of laminated plates. This case of simply supported boundary conditions is evidently used to test the reliability of the FE model, by comparing its results with existing exact elasticity solution [36]. Hence, 
after the reliability of the proposed FE model has been successfully validated, stress analysis of free-edge problem under mechanical and thermal loads are investigated.

\subsection{Bending of $\left[0^{\circ} / 90^{\circ} / 0^{\circ}\right]$ laminate under sinusoidal transverse loading}

Consider a rectangular simply supported cross-ply laminate of dimension $a=$ $b$ an thickness $h$ with equal thickness for each layer. subjected to a double sinusoidal transverse load $q=q_{o} \sin \left(\frac{\pi x}{a}\right) \sin \left(\frac{\pi y}{b}\right)$. For the purpose of validating the multi-particle finite element, the following Pagano's choice of material [36] has been used:

$E_{1} / E_{2}=25, \quad E_{2}=E_{3}=7 \mathrm{GPa}$

$G_{12}=G_{13}=0.5 E_{2}, \quad G_{23}=0.2 E_{2}$

$\nu_{L T}=\nu_{T N}=\nu_{L N}=0.25$

where the subscripts 1, 2, 3 signify the direction parallel to the fibres, the transverse direction perpendicular to the fibres, and the out-of-plane direction, respectively. The results of the multi-particle FE calculation will be compared with Pagano's exact three-dimensional elasticity solutions for thick laminate $(a=4 h)$.

Due to the symmetry of the problem, only one quadrant of the plate is modelled $(0<x<a / 2,0<y<a / 2)$ by a $5 \times 5$ mesh. The numerical results shown here are presented by means of the following normalised stresses as the same form of Pagano [36]:

$\bar{\sigma}_{z}=\frac{\sigma_{z}}{q_{o}}, \quad\left(\bar{\sigma}_{x z}, \bar{\sigma}_{y z}\right)=\left(\sigma_{x z}, \sigma_{y z}\right) \frac{h}{q_{o} a}$ 
As previously mentioned, in the multi-particle modelling, each actual physical layer in a laminate can be treated as if it is made of as many layers as it is wished with, of course, the same fibre direction as the actual layer. The present FE model provide only direct access to the interfacial stresses by constitutive equations. Hence, one must use this sublayer modelling to study through-the-thickness stresses distributions. In Figs. 2-4 out-of-plane stresses distributions by six and one sub-layers FE modelling are plotted. The result of three-dimensional elasticity solution [36] is also reported for comparison. Excellent agreement between the multi-particle FE solution and the exact three-dimensional elasticity solution is found. This close agreement verifies the accuracy of the present finite element. It is shown in this case that regardless of the used sublayer number, interfacial stresses values do not change. Increasing the numerical layer number only helps to reproduce the stress distribution shape and does not affect the result's precision.

\subsection{Free-edge laminate under uniform axial extension}

In what follows, the classical straight free-edge problem are considered. This problem have been studied by several investigators. Certain similarities are observed in these results, however there are also numerous discrepancies, notably in the prediction of interlaminar stresses near free edges. It is reminded here that no exact elasticity solution to this free-edge problem has been yet founded. All the results obtained are merely based on approximate analytical and numerical analyses. For most of these investigations, the longitudinal degrees of freedom in the displacement field is neglected and the stress analysis is then restricted to a generic two-dimensional cross-section of the laminates. 
In this investigation, general finite dimension laminates with the ply configuration $\left[0^{\circ} / 90^{\circ}\right]_{s},\left[90^{\circ} / 0^{\circ}\right]_{s}$ are assumed to have the length $2 a$, width $2 b$, and thickness $h=4 e$, with $b=8 e$ and $a=2 b$ (see Fig. 5). The laminate is subjected to a prescribed uniform axial strain $\varepsilon_{x}=\frac{\Delta}{a}$. The material properties are taken to be those of a high-modulus graphite/epoxy. The elasticity constants with respect to principal material axis of each ply are:

$$
\begin{aligned}
& E_{1}=137,90 \mathrm{GPa} \\
& E_{2}=E_{3}=14,48 \mathrm{GPa} \\
& G_{12}=G_{13}=G_{23}=5,86 \mathrm{GPa} \\
& \nu_{12}=\nu_{13}=\nu_{23}=0,21
\end{aligned}
$$

Due to the symmetry of the problem, only one quadrant of the plate is modelled $(0<x<a, 0<y<b)$. Convergence (influence of the mesh pattern) study has been performed in [1] and is not presented here. As opposed to 3D FE analysis [4-7] the multi-particle FE presents converge finite stresses at free edges. Even a coarse mesh $(5 \times 5$ elements $)$ as shown in Fig. 5 assures a very good convergence. The following results are evaluated with this $5 \times 5$ mesh.

Fig. 6 shows the $\sigma_{y z}$ distribution at the $0^{\circ} / 90^{\circ}$ interface of a $\left[0^{\circ} / 90^{\circ}\right]_{s}$ laminate under uniform axial extension. Each physical ply is modelled by one numerical layer. Results of 3D FE by Wang \& Crossman [4] and by Carreira [19], and Pagano's local model [9] are also plotted for comparison. It can be seen that for $y / b<0.8$ the interlaminar stress $\sigma_{y z}$ obtained by all the calculations are very close, however for $0.8 \leq y / b \leq 1.0$ as the free edge is approached, these distributions exhibit obvious differences. The results obtained by the use of a special 3D FE procedure [19] for better convergence than classical one are in good agreement with present method. Note that Wang \& Crossman's results 
have been obtained using an arbitrate mesh where convergence is not assured due to the stress singularity at the edge.

The shear stress fields $\sigma_{y z}$ in Pagano's model verify the free edge conditions (vanish of shear stress at free edge). For the present FE model, this boundary condition is only energetically taken in to account. Nevertheless the evaluation of the shear stress shape is very accurate. Except at the $0^{\circ} / 90^{\circ}$ interface, the value of $\sigma_{y z}$ is quite close to zero (see Fig. 7). The steepness of stress gradient at the ply interface, particularly near the free edge is often attributed to a singularity at the $0^{\circ} / 90^{\circ}$ interface in conventional 3D FE investigations [4-7]. Due to the mesh dependency of these models, the stress values on the edge are meaningless and prevent the use of a direct strength of materials approach to predicting delamination onset. As mention above the present model provides useful finite stress on the edge which can be used directly in a limit stress criterion as shown in [37]. The present finite interfacial stresses are in this sense equivalent to the averages of the 3D FE's stresses over a characteristic distance from the edge as used in several delamination onset investigations $[39,40]$.

The distribution of $\sigma_{y z}$ through thee thickness at the free edge $(y=0.98 b)$ of the $\left[0^{\circ} / 90^{\circ}\right]_{s}$ laminate is presented in Fig. 7. Each physical ply is modelled by the same $N$ sublayer. Note that the inconvenient of all the models based on layer-wise theory is that the calculation's volume depends on the number of numerical layers and becomes very large with the increasing of the former. Moreover, in many layer-wise models [16,17], free-edge stresses are noticeably dependent on the sublayer division $N$ and one has to incriease $N$ to assure the convergence ( $N$ must be larger than 6 in $[16])$. It is seen in Fig. 7 that the stress fields obtained by the present model are not affected by the sublayer 
division number. The multi-particle model employed here is very general in that the subdivision number can be greater, equal or less than the number of material layers $n$. Also the number of sublayer division can vary from layer to layer. Hence one can use a large number of sublayers in the interested material layer and a small number of numerical layers elsewhere which is very useful in the investigation of a multilayer laminate with a very large number of material layers. Fig. 8 shows an illustrated case where the $0^{\circ}$ ply of a $\left[0^{\circ} / 90^{\circ}\right]_{s}$ is modelled by 9 and 17 numerical layers and one numerical layer is used for other plies. Again a very good convergence is obtained that confirms the non existence of singularity in our model.

Fig. 9 shows the $\sigma_{z}$ distribution at the $0^{\circ} / 90^{\circ}$ interfaces of $\left[0^{\circ} / 90^{\circ}\right]_{s}$ and $\left[90^{\circ} / 0^{\circ}\right]_{s}$ laminates. It is noted here that the same quality of convergence has been found and an uniform sublayer division $N=5$ is used to reproduce the stress shape. The results of the present model and those of Wang \& Crossman [4] are in excellent agreement. The through-the-thickness distribution of $\sigma_{z}$ at the free edge in a $\left[0^{\circ} / 90^{\circ}\right]_{s}$ laminate is shown in Fig. 10 in comparison with some results found in the literature. Except a similarity of overall shape, all the considered models provide a dispersion both in magnitude and in local shape gradient. Results of Flanagan [14] and Cho \& Kim [27] have been obtained using stress functions and principle of complementary energy. Their results shows a pronounced singularity of stress fields in the edge that explains the large values of $\sigma_{z}$ in Fig. 10. In the work of Tian et al. [30], a 3D hybrid stress element has been used to investigate free-edge stress distribution. The values of interfacial stresses of the present model and those of [30] are quite close and both models confirm no existence of stress singularity at the interface.

The through-the-thickness distribution of $\sigma_{z}$ the free edge in a $\left[90^{\circ} / 0^{\circ}\right]_{s}$ lam- 
inate is plotted in Fig. 11. Excellent agreement between the present solutions and those of Tahani \& Nosier [16] and Wang \& Crossman [4] is found for this case.

\subsection{Free-edge laminate under thermal loading}

In this section, $\left[0^{\circ} / 90^{\circ}\right]_{s},\left[90^{\circ} / 0^{\circ}\right]_{s}$ and $\left[45^{\circ} /-45^{\circ}\right]_{s}$ free-edge laminates subjected to thermal loading (residual stress due to the curing process) are considered. The results are compared with 3D FE results $[19,41]$ and those of stress function based method $[27,42]$. The following material is used for this investigation:

$E_{1}=137,90 \mathrm{GPa}$

$E_{2}=E_{3}=14,48 \mathrm{GPa}$

$G_{12}=G_{13}=G_{23}=5,86 \mathrm{GPa}$

$\nu_{12}=\nu_{13}=\nu_{23}=0,21$

$\alpha_{1}=0.36 \times 10^{-6^{\circ}} C^{-1}, \alpha_{2}=\alpha_{3}=28.8 \times 10^{-6^{\circ}} C^{-1}$

Cross-ply laminates: Figs. 12 and 13 show the distribution of interlaminar stresses at the $0^{\circ} / 90^{\circ}$ interface of laminate $\left[0^{\circ} / 90^{\circ}\right]_{s}$ laminate under uniform temperature variation $\Delta T=1^{\circ} C$. The $5 \times 5$ mesh as in the later example that provides a very good quality of convergence has been used. A very good agreement between all the models considered has been obtained. All of these calculations predict a compression at free edge interface for a $1^{\circ} \mathrm{C}$ temperature variation (see Fig. 12).

Through-the-thickness distribution of $\sigma_{z}$ at the free edge of $\left[90^{\circ} / 0^{\circ}\right]_{s}$ laminate for a $1^{\circ} \mathrm{C}$ temperature variation is plotted in Fig 14 using a sublayer division 
$N=5$. The present stress value at the $0^{\circ} / 90^{\circ}$ interface is quite close to these of Cho \& Kim [27]. At the $0^{\circ} / 0^{\circ}$ interface the present model provides a larger stress value.

Angle-ply laminate: In this example, a rectangular $\left[-45^{\circ} / 45^{\circ}\right]_{s}$ of dimension $b=8 e$ and $a=10 b$ is investigated. The symmetry of the problem is no longer verified in this case. Hence the whole laminate is modelled by the present FE model. A typical $20 \times 10$ mesh is presented in Fig 15 .

Figs. 16 and 17 show interlaminar stresses distributions at different interfaces. Once again, the present model and 3D FE [41] provide almost the same results.

\section{Conclusions}

In this study, free-edge laminates subjected to uniaxial extension and uniform temperature variation are investigated using multi-particle finite element. This two-dimensional finite element approach with very coarse mesh, provides very accurate three-dimensional free-edge stress field. Moreover the present model allows a flexible choice of sublayer scheme in order to investigate through thickness local variation of stress fields. Detail investigation of the solution's sensibility again the number of sublayer division is also given. Regardless of the used sublayer's number, the results stay practically identical. Increasing the subdivisions number is useful to reproduce shape distribution and does not affect the precision. This study confirms no existence of stress singularity at the interface. 


\section{References}

[1] V.T. Nguyen, J.F. Caron "A new finite element for free edge effect analysis in laminated composites", Computers \& Structures., 2005 (accepted for publication).

[2] R. B. Pipes, N. J. Pagano "Interlaminar stresses in composite laminates under uniform axial extension", J. Comput. Mater., 4, 538-548, 1970.

[3] E. F. Rybichi "Approximate three-dimensional solutions for symmetric laminates under in plane loading”, J. Comput. Mater., 5, 354-360, 1971.

[4] A. S. D. Wang, F. W. Crossman "Some new results on the edge effect in symmetric composite laminates", J. Compos. Mater., 11, 92-106, 1977.

[5] I. S. Raju, J. H. Crews "Interlaminar stress singularities at a straight free edge in composite laminates", Comput. Struct., 14, 21-28, 1981.

[6] L. B. Lessard, A. S. Schmidt, M. M. Shokrieh "Three-dimensional stress analysis of free-edge effects in a simple composite cross-ply laminate", Int. J. Solids Struct., 33(15), 2243-2259, 1996.

[7] U. Icardi, A. M. Bertetto "An evaluation of the influence of geometry and of material properties at free edges and at corners of composite laminates", Computers \& Structures, 57, 555-571, 1995.

[8] W. Becker "Closed-form solution for the free-edge effect in cross-ply laminates", Compos. Struct., 26, 39-45, 1993.

[9] N. J. Pagano "Stress fields in composite laminates", Int. J. Solids Struct., 14, 385-400, 2004.

[10] C. Kassapoglou, P.A. Lagace "Closed form solutions for the interlaminar stress field in angle-ply and cross-ply laminates", J. Comput. Mates., 21, 292-308, 1987. 
[11] S. Tang, A. Levy "A boundary layer theory - part II: extension of laminated finite strip", J. Compos. Mater., 9, 42-52, 1975.

[12] S. S. Wang, I. Choi "Boundary-layer effects in composite laminates: part 1 free-edge stress singularities", ASME J. Appl. Mech., 49, 541-548, 1982.

[13] S. S. Wang, I. Choi "Boundary-layer effects in composite laminates: part 2 free-edge stress singularities", ASME J. Appl. Mech., 49, 549-560, 1982.

[14] G. Flanagan "An efficient stress function approximation for the free-edge stresses in laminates", Int. J. Solids Struct., 31, 941-952, 1994.

[15] J.N. Reddy "A generalization of two-dimensional theories of laminated composite plates", Commun. Appl. Numer. Meth., 3, 173-180, 1987.

[16] M. Tahani, A. Nosier "Three-dimensional interlaminar stress analysis at free edges of general cross-ply composite laminates", Materials and Design, 24, 121$130,2003$.

[17] M. Tahani, A. Nosier "Free edge stress analysis of general cross-ply composite laminates under extension and thermal loading", Composite Structures, 60, 91$103,2003$.

[18] T. Kant, K. Swaminathan "Estimation of transverse/interlaminar stresses in laminated composites - a selective review and survey of current developments", Composite Structures, 49, 65-75, 2000.

[19] R.P. Carreira, J.F. Caron, A. Diaz Diaz "Model of multilayered materials for interface stresses estimation and validation by finite element calculations", Mechanics of Materials, 34, 217-230, 2002.

[20] Y. M. Wang, J. Q. Tarn, C. K. Hsu "State space approach for stress decay in laminates", Int. J. Solids Struct., 37, 3535-3553, 2000. 
[21] J. Q. Ye, H. Y. Sheng, Q. H. Qin “A state space finite element for laminated composites with free edges and subjected to transverse and in-plane loads", Computers \& Structures, 82, 1131-1141, 2004.

[22] D. Zhang, J. Ye, H. Y. Sheng "Free-edge and ply cracking effect in cross-ply laminated composites under uniform extension and thermal loading", Composite Structures, in press, 2005.

[23] P. W. Hsu, C. T. Herakovich "Edge effects in angle-ply composite laminates", J. Compos. Mater., 11, 422-428, 1977.

[24] R. B. Pipes, N. J. Pagano "Interlaminar stresses in composite laminates - an approximate elasticity solution", ASME. J. Appl. Mech., 41, 668-672, 1974.

[25] W. L. Yin "Free edge effects in anisotropic laminates under extension, bending and twisting. Part I: A stress-function-based variational approach", ASME. J. Appl. Mech., 61, 410-415, 1994.

[26] W. L. Yin "Free edge effects in anisotropic laminates under extension, bending and twisting. Part II: Eigenfunction analysis and the results for symmetric laminates", ASME. J. Appl. Mech., 61, 416-421, 1994.

[27] M. Cho, H. S. Kim "Iterative free-edge stress analysis of composite laminates under extension, bending, twisting and thermal loadings", Int. J. Solids Struct., 37(3), 435-459, 2000.

[28] R. L. Spilker, S. C. Chou "Edge effects in symmetric composite laminates: importance of satisfying the traction free-degree condition", J. Comput. Mater., $14,2-20,1980$.

[29] W. J. Liou, C. T. Sun “A three-dimensional hybrid stress isoparametric element for the analysis of lamianted composite plates", Comput. Struct., 25, 241-249, 1987. 
[30] Z. Tian, F. Zhao, Q. Yang "Straight free-edge effects in laminated composites", Finite Elements in Analysis and Design, 41, 1-14, 2004.

[31] T. H. H. Pian "Derivation of stiffness matrices by assumed stress distributions", AIAA Journal, 2, 1333, 1964.

[32] I. Kimpara, K. Kageyama, K. Suzuki "Finite element stress analysis of interlayer based on selective layerwise higher-order theory", Composite Part A, 29, 1049-1056, 1998.

[33] J.F. Caron, A. Ehrlacher "Modelling the kinetics of transverse cracking in composite laminates”, Compos. Sci. Technol., 57, 1261-1270, 1997.

[34] T. Naciri, A. Ehrlacher, A. Chabot "Interlaminar stress analysis with a new multiparticle modelization of multilayered materials (M4)", Compos. Sci. Technol., 58, 337-343, 1998.

[35] A. Diaz Diaz, J. F. Caron, R. P. Carreira "Software application for evaluating interfacial stresses in inelastic symmetrical laminates with free edges", Composite Structures, 58, 195-208, 2002.

[36] N. J. Pagano "Exact solutions for rectangular bidirectional composites and sandwich plates", J. Compos. Mater., 4, 20-34, 1970.

[37] J. F. Caron, A. Diaz Diaz, R. P. Carreira, A. Chabot, A. Ehrlacher "Multiparticle modelling for the prediction of delamination in multi-layered materials", Compos. Sci. Technol., in press, 2005.

[38] E. Hinton, D. R. J. Owen "Finite element programming", Academic Press, London, 1977.

[39] J. C. Brewer, P. A. Lagace "Quadratic stress criterion for initiation of delamination”, J. Compos. Mater., 22, 1141-1155, 1988. 
[40] D. Leguillon, G. Marion, R. Harry, F. Lecuyer "The onset of delamination at stress free-edges in angle-ply laminates - analysis of two criteria", Compos. Sci. Technol., 61, 377-382, 2001.

[41] A. S. D. Wang, F. W. Crossman "Edge effects on thermally-induced stresses in composite laminates", J. Compos. Mater., 11, 300., 1977.

[42] W. L. Yin "The effect of temperature gradient on the free-edge interlaminar stresses in multi-layered structures", J. Compos. Mater., 31, 2460-2477, 1997. 


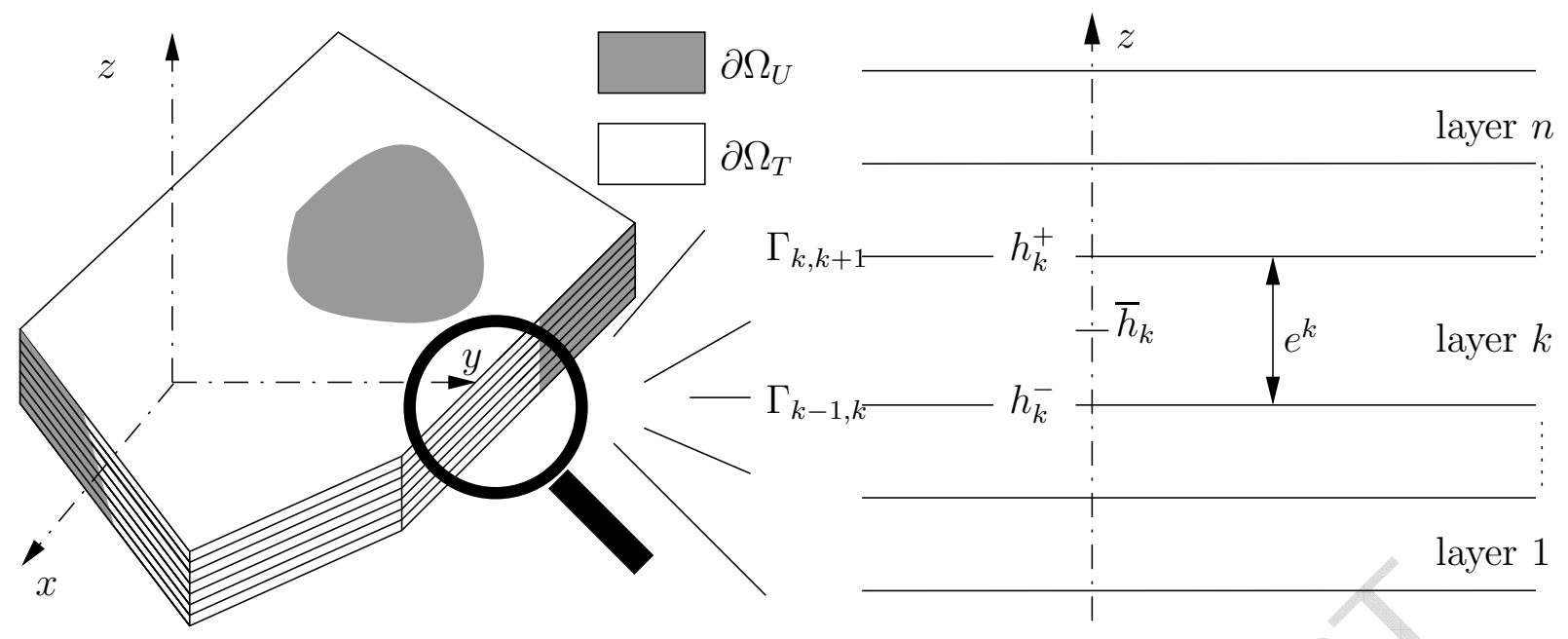

Fig. 1. Stacking sequence of a laminated plate. 


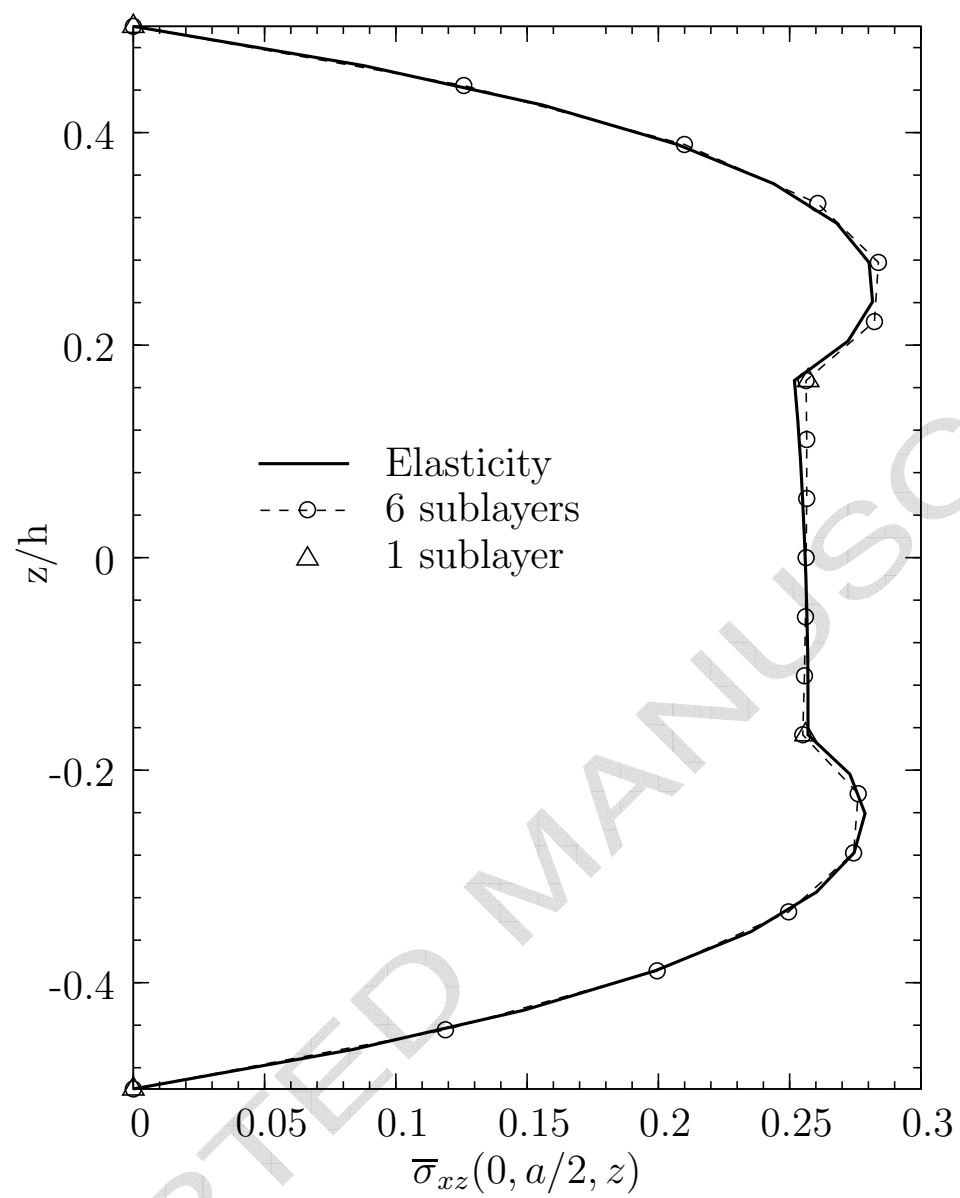

Fig. 2. Distribution of shear stress $\sigma_{x z}$ through the thickness of a simply supported rectangular laminate under sinusoidal transverse loading. 


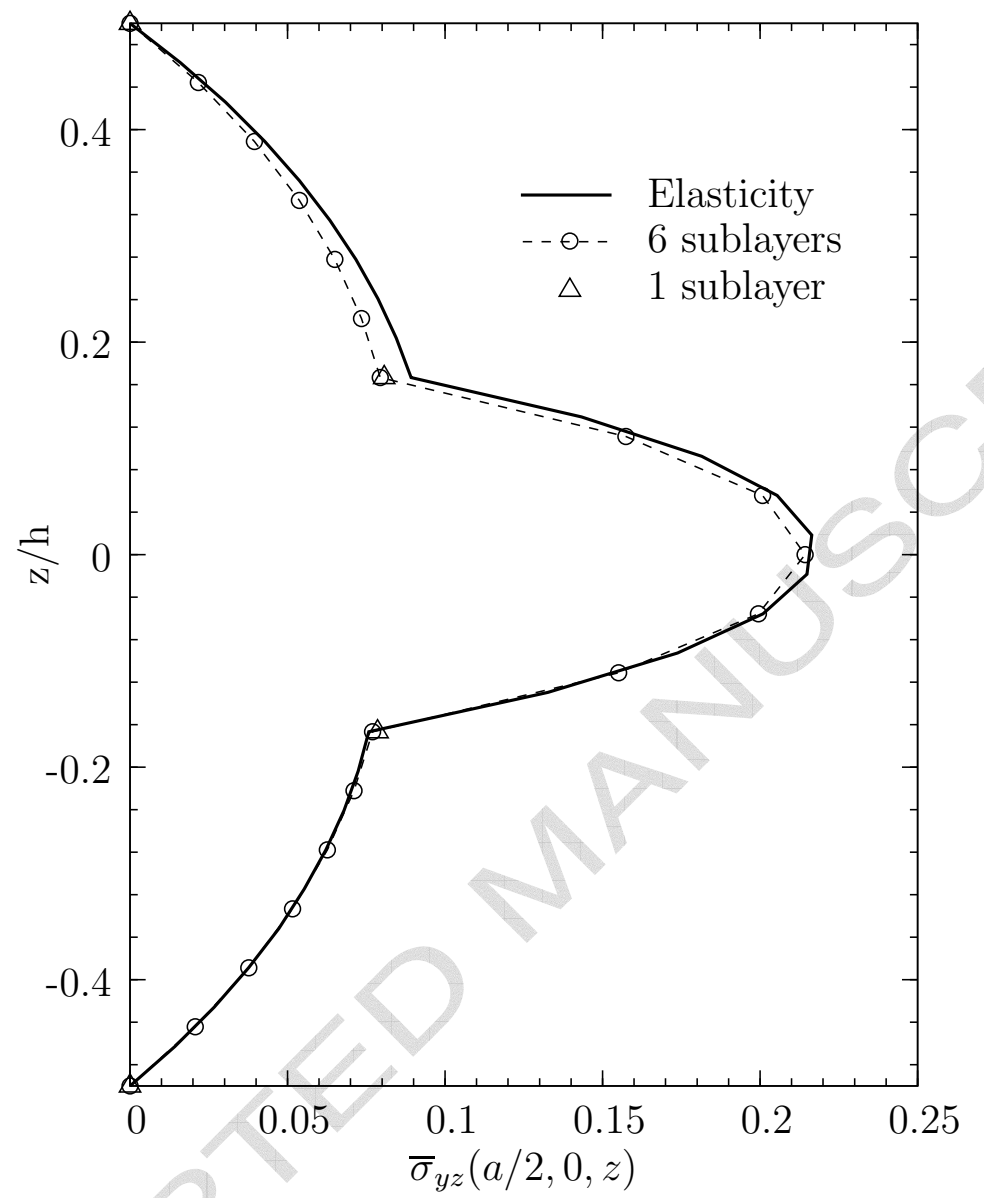

Fig. 3. Distribution of shear stress $\sigma_{y z}$ through the thickness of a simply supported rectangular laminate under sinusoidal transverse loading. 


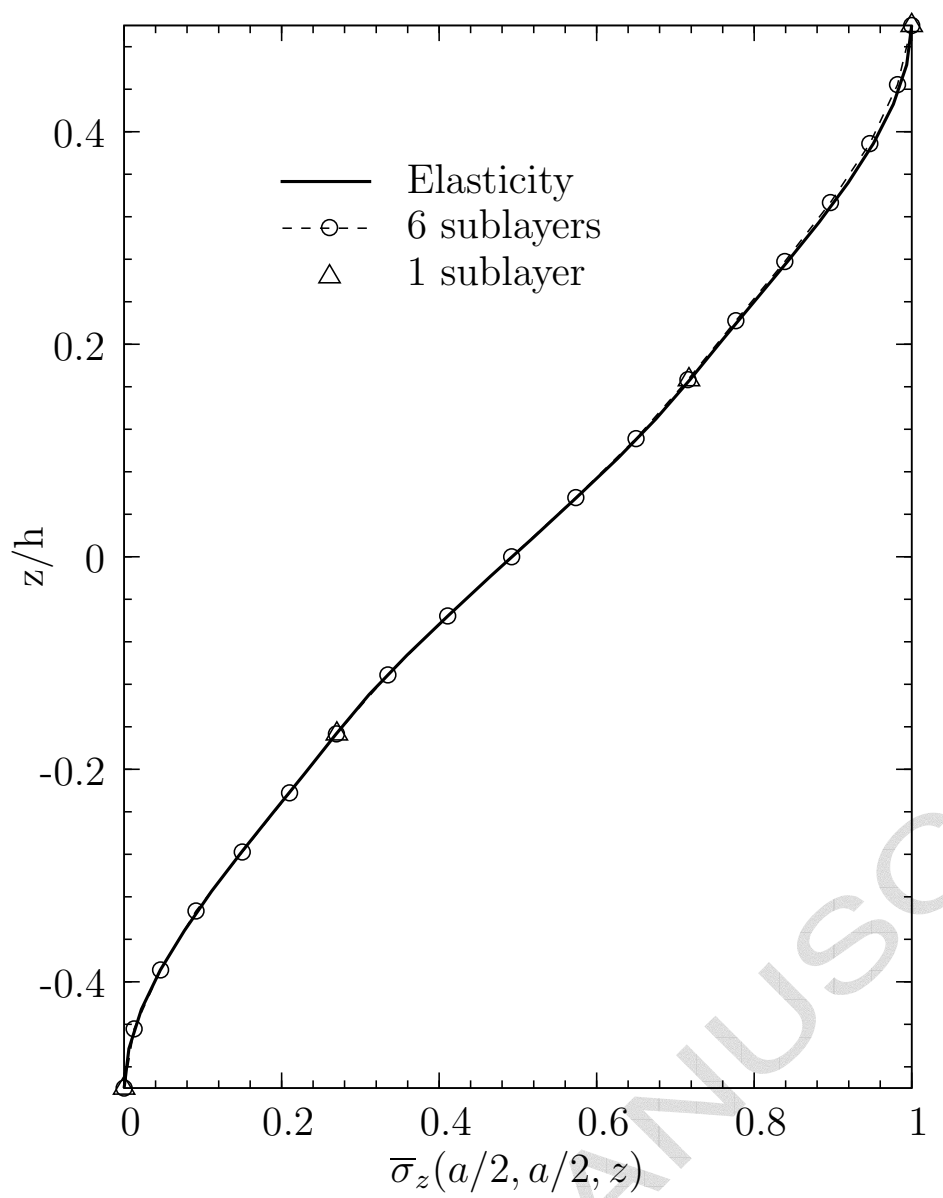

Fig. 4. Distribution of normal stress $\sigma_{z}$ through the thickness of a simply supported rectangular laminate under sinusoidal transverse loading.

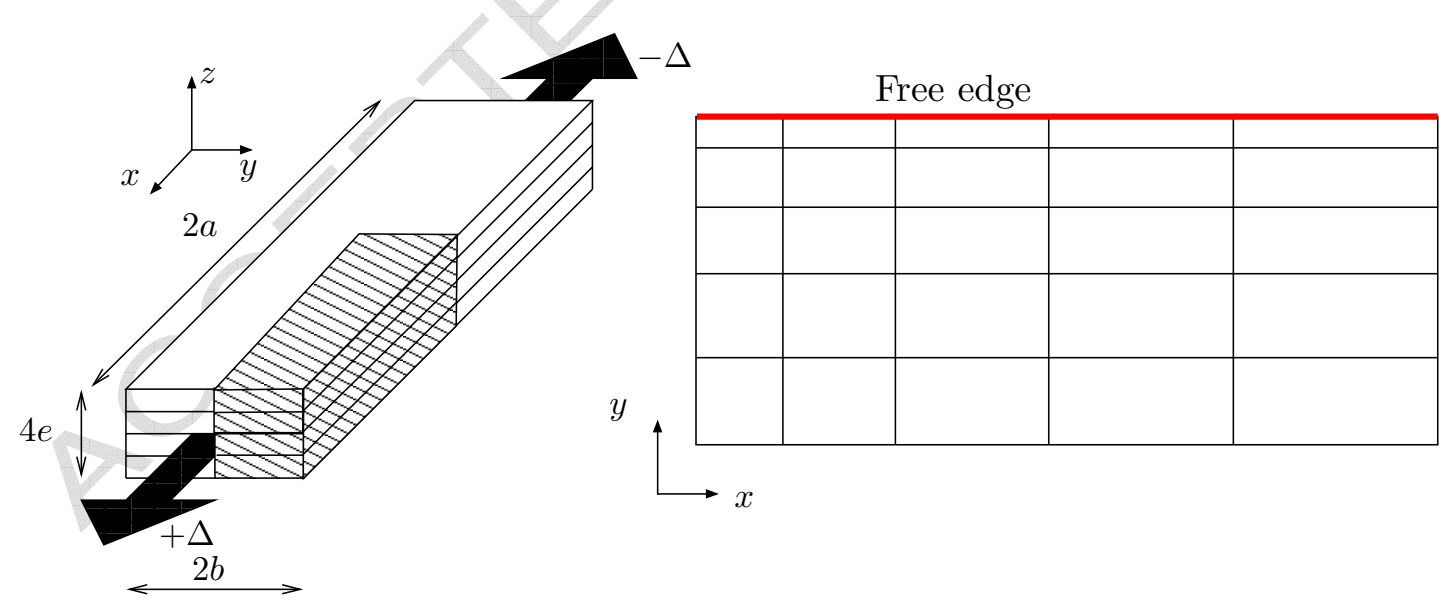

Fig. 5. Laminate subjected to uniform axial extension - typical mesh pattern. 


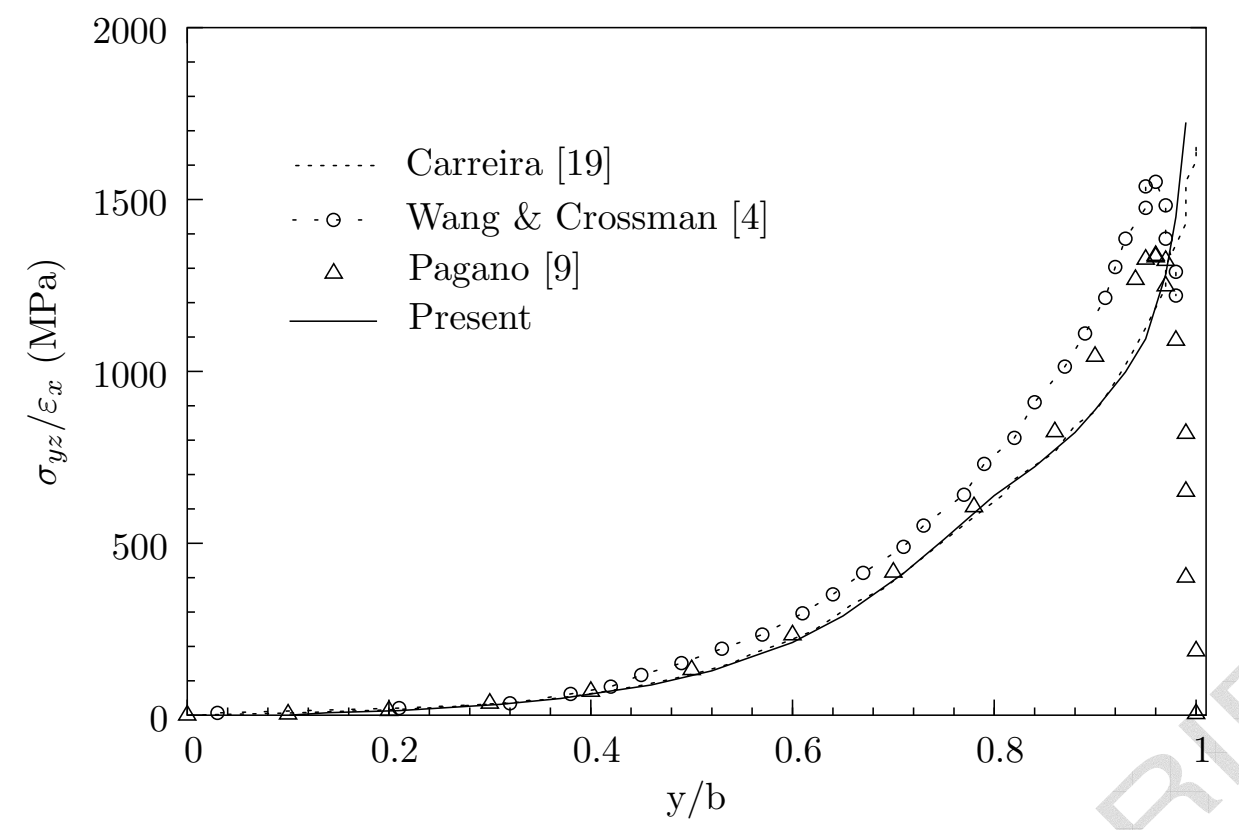

Fig. 6. Distribution of interlaminar shear stress $\sigma_{y z}$ along the $0^{\circ} / 90^{\circ}$ interface of $\left[0^{\circ} / 90^{\circ}\right]_{s}$ laminate under uniform axial extension.

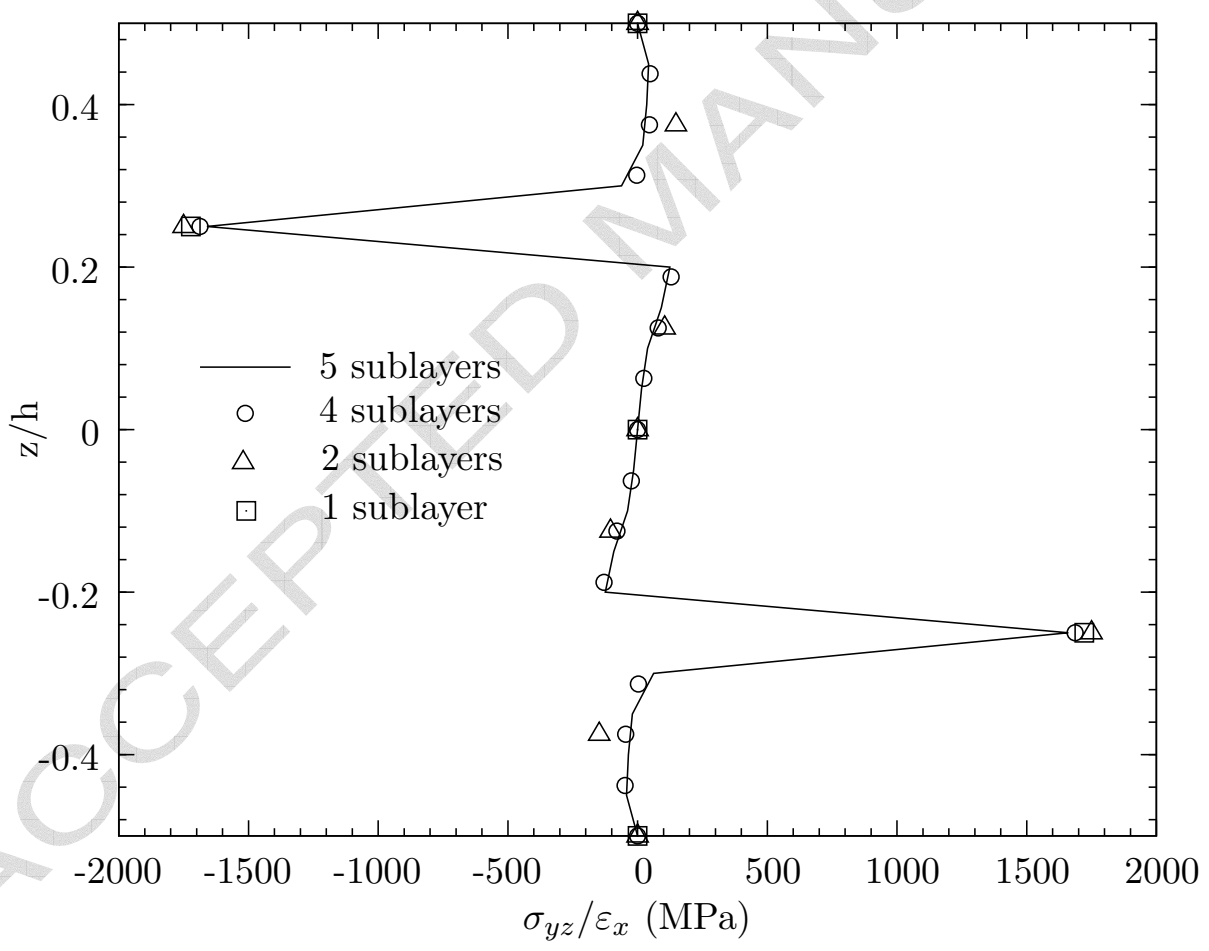

Fig. 7. Distribution of shear stress $\sigma_{y z}$ versus $z$ at the free edge of $\left[0^{\circ} / 90^{\circ}\right]_{s}$ laminate under uniform axial extension: influence of the number of modelised sub-layers. 


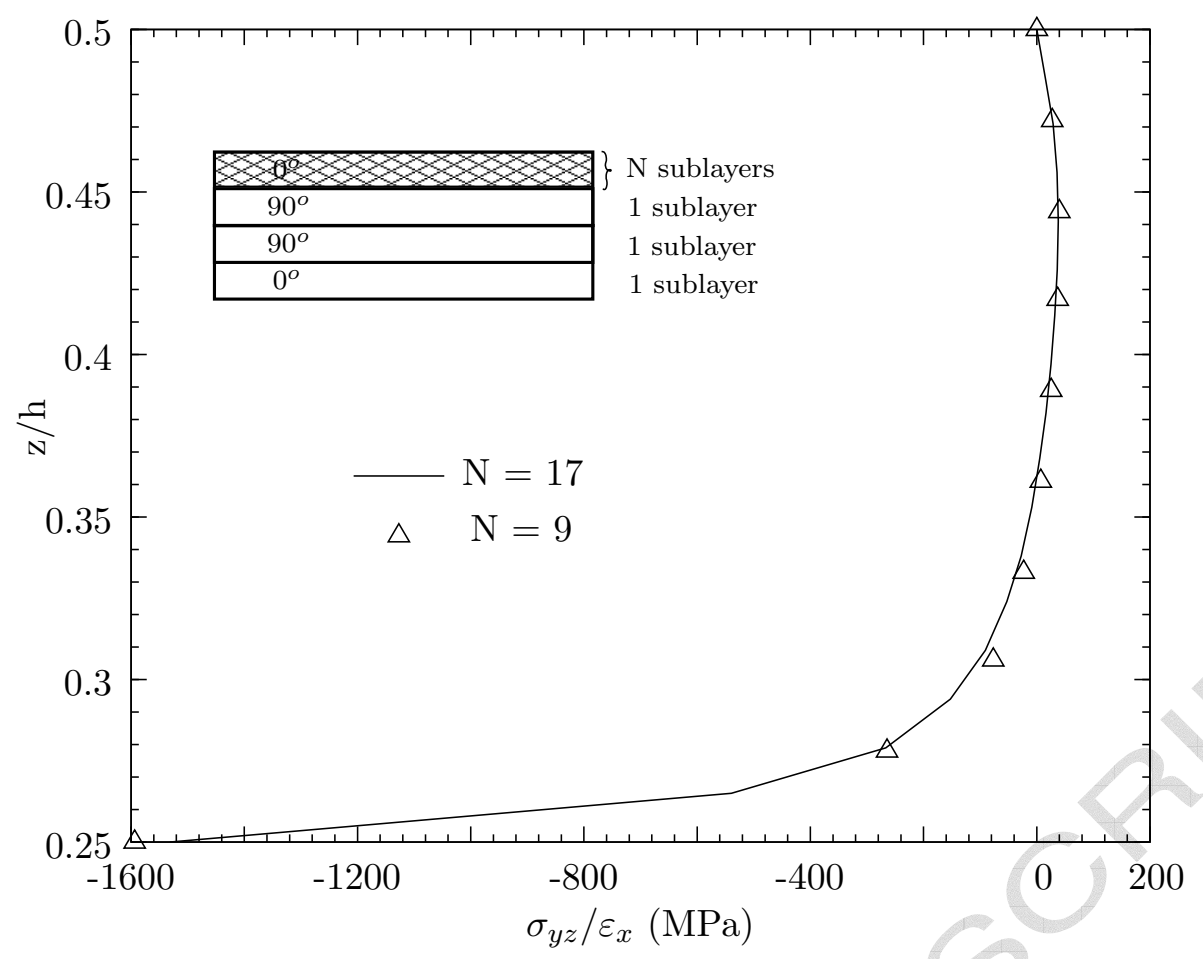

Fig. 8. Distribution of shear stress $\sigma_{y z}$ at the free edge of the $0^{\circ}$ ply of $\left[0^{\circ} / 90^{\circ}\right]_{s}$ laminate under uniform axial extension.

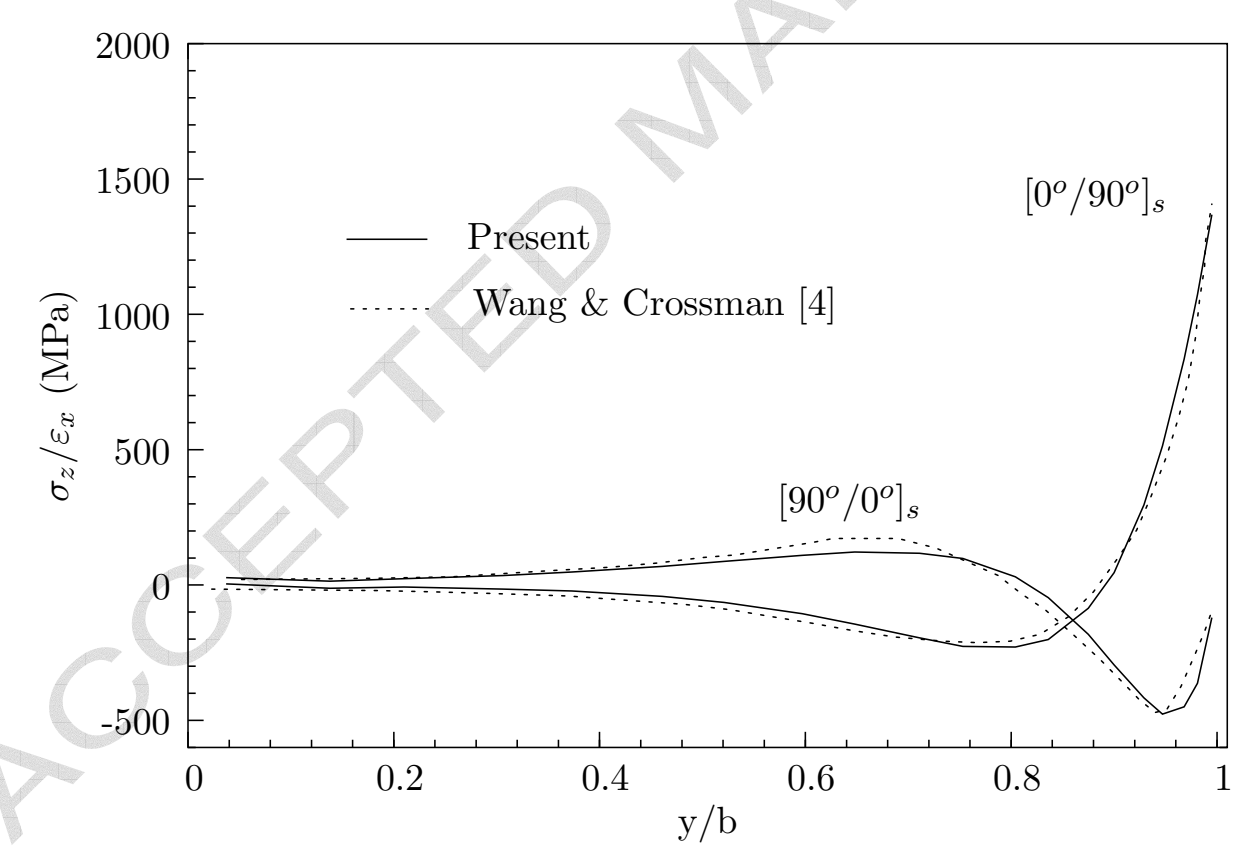

Fig. 9. Distribution of interlaminar normal stress $\sigma_{z}$ along the $0^{\circ} / 90^{\circ}$ interface of $\left[0^{\circ} / 90^{\circ}\right]_{s}$ and $\left[90^{\circ} / 0^{\circ}\right]_{s}$ laminates under uniform axial extension. 


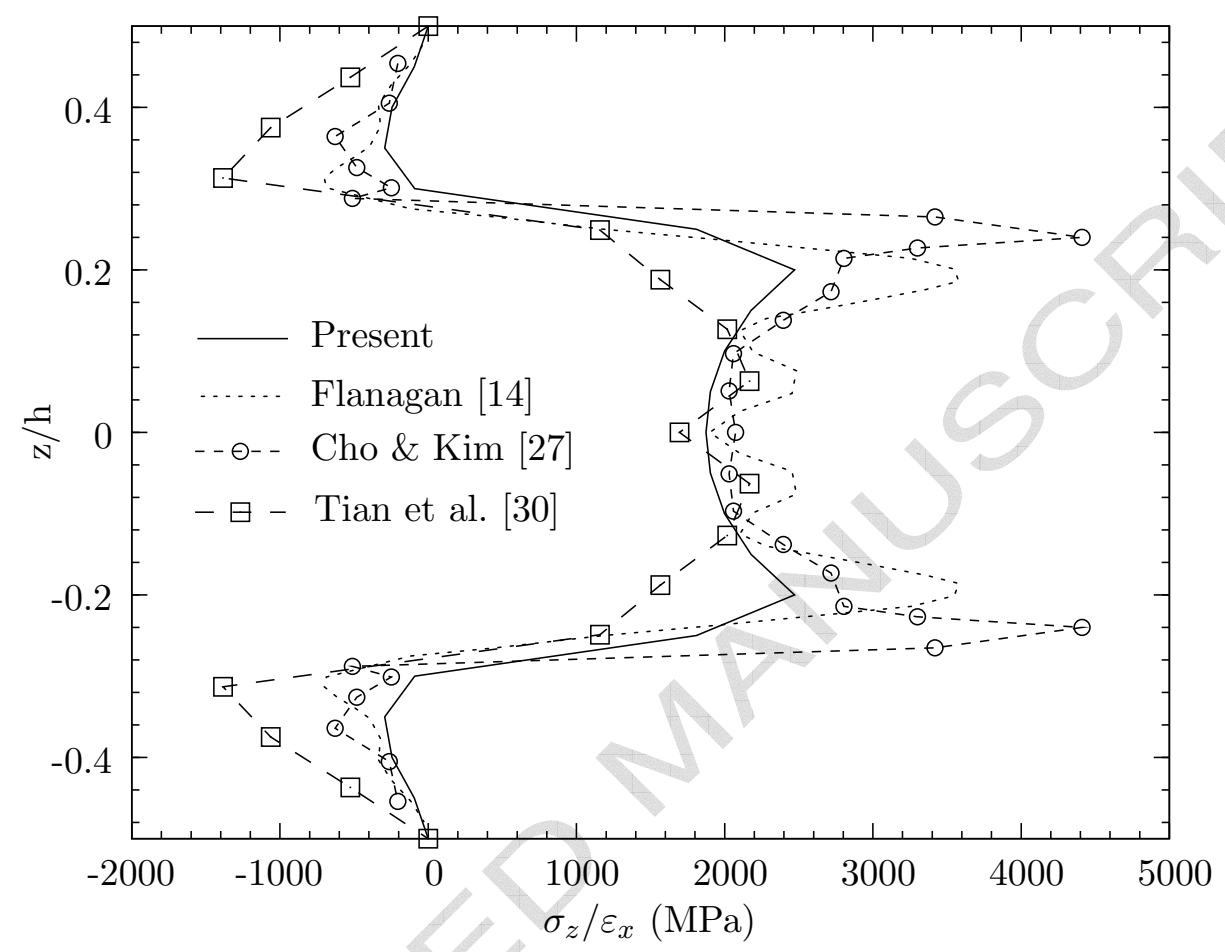

Fig. 10. Distribution of normal stress $\sigma_{z}$ versus $z$ at the free edge of $\left[0^{\circ} / 90^{\circ}\right]_{s}$ laminate under uniform axial extension. 


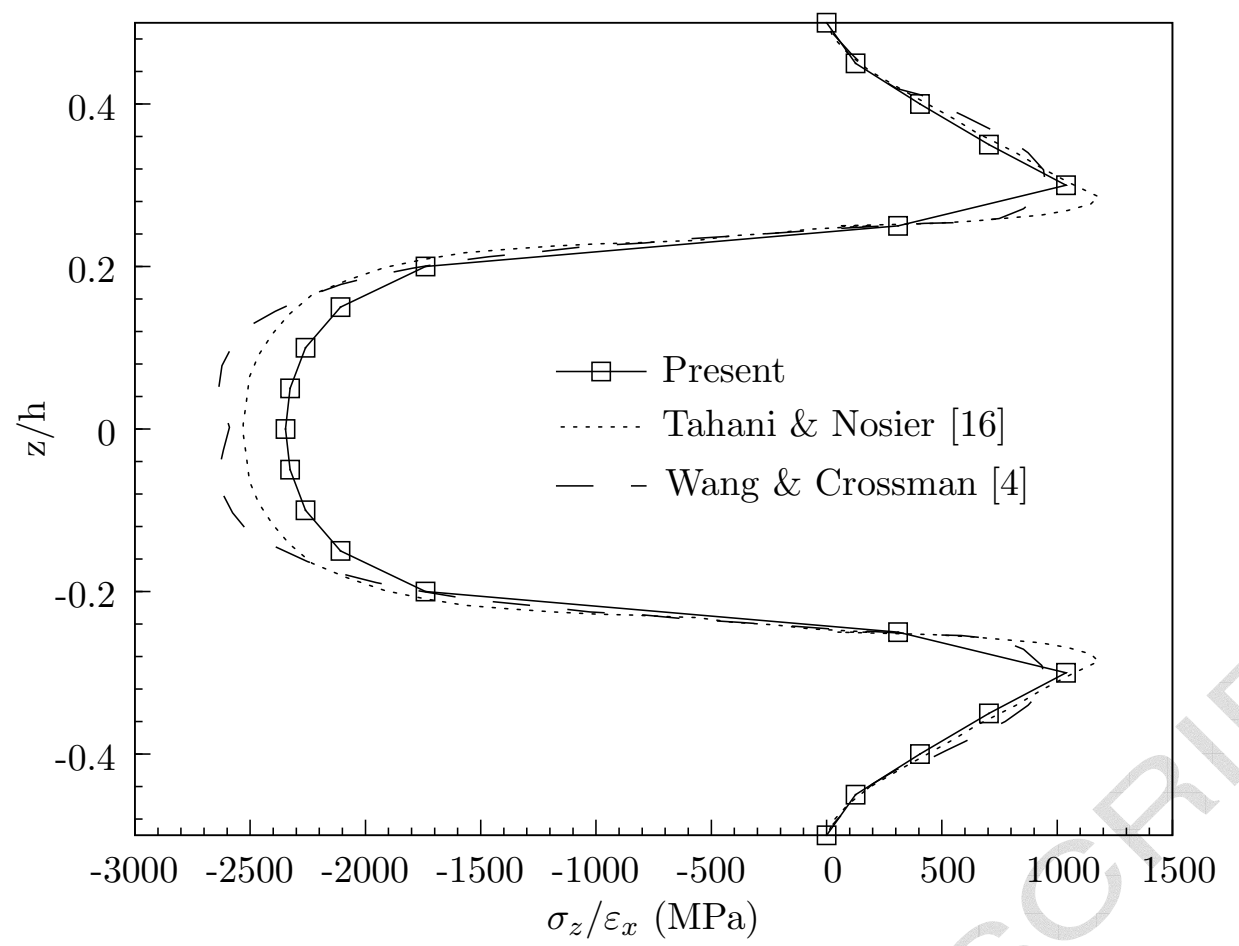

Fig. 11. Distribution of normal stress $\sigma_{z}$ versus $z$ at the free edge of $\left[90^{\circ} / 0^{\circ}\right]_{s}$ laminate under uniform axial extension.

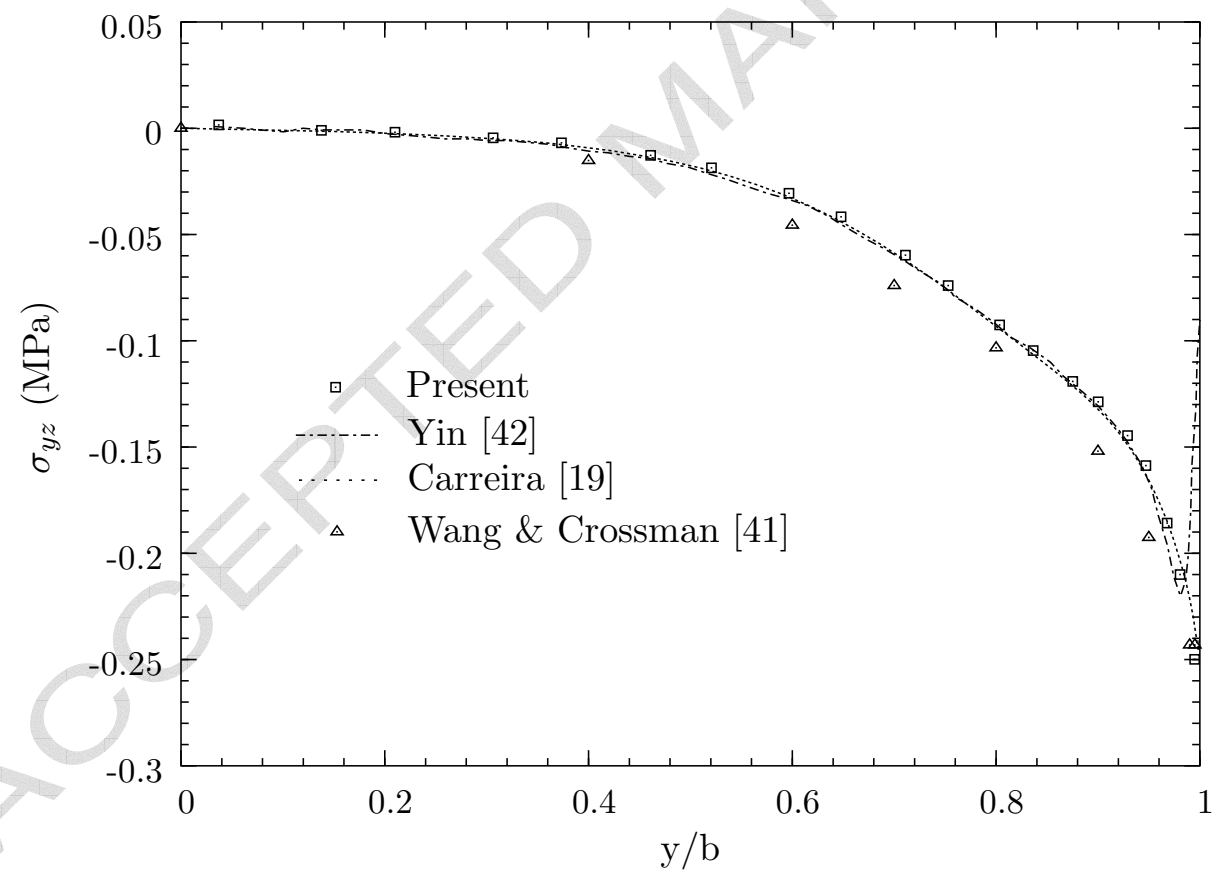

Fig. 12. Distribution of interlaminar shear stress $\sigma_{y z}$ along the $0^{\circ} / 90^{\circ}$ interface of $\left[0^{\circ} / 90^{\circ}\right]_{s}$ laminate under $\Delta T=1^{\circ} \mathrm{C}$. 


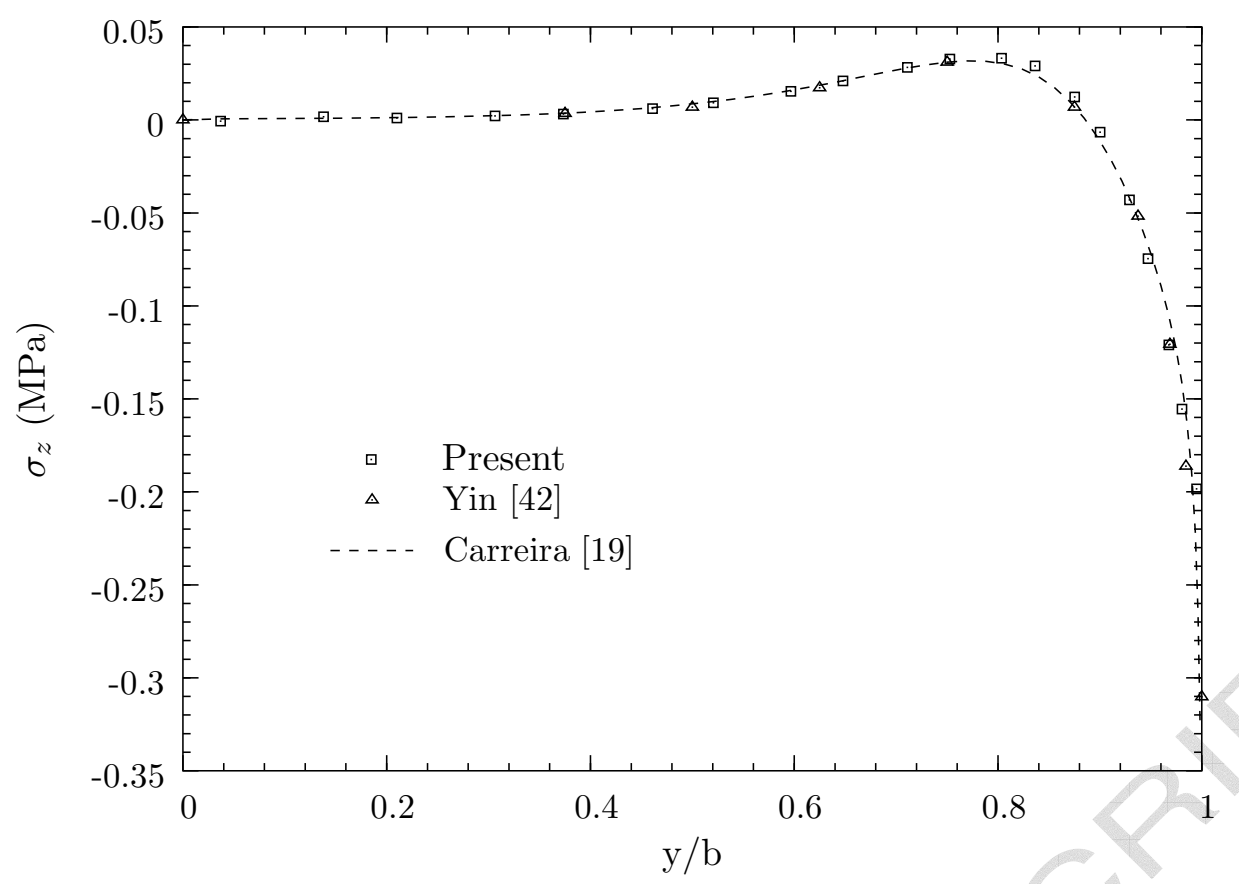

Fig. 13. Distribution of interlaminar normal stress $\sigma_{z}$ along the $0^{\circ} / 90^{\circ}$ interface of $\left[0^{\circ} / 90^{\circ}\right]_{s}$ laminate under $\Delta T=1^{\circ} \mathrm{C}$.

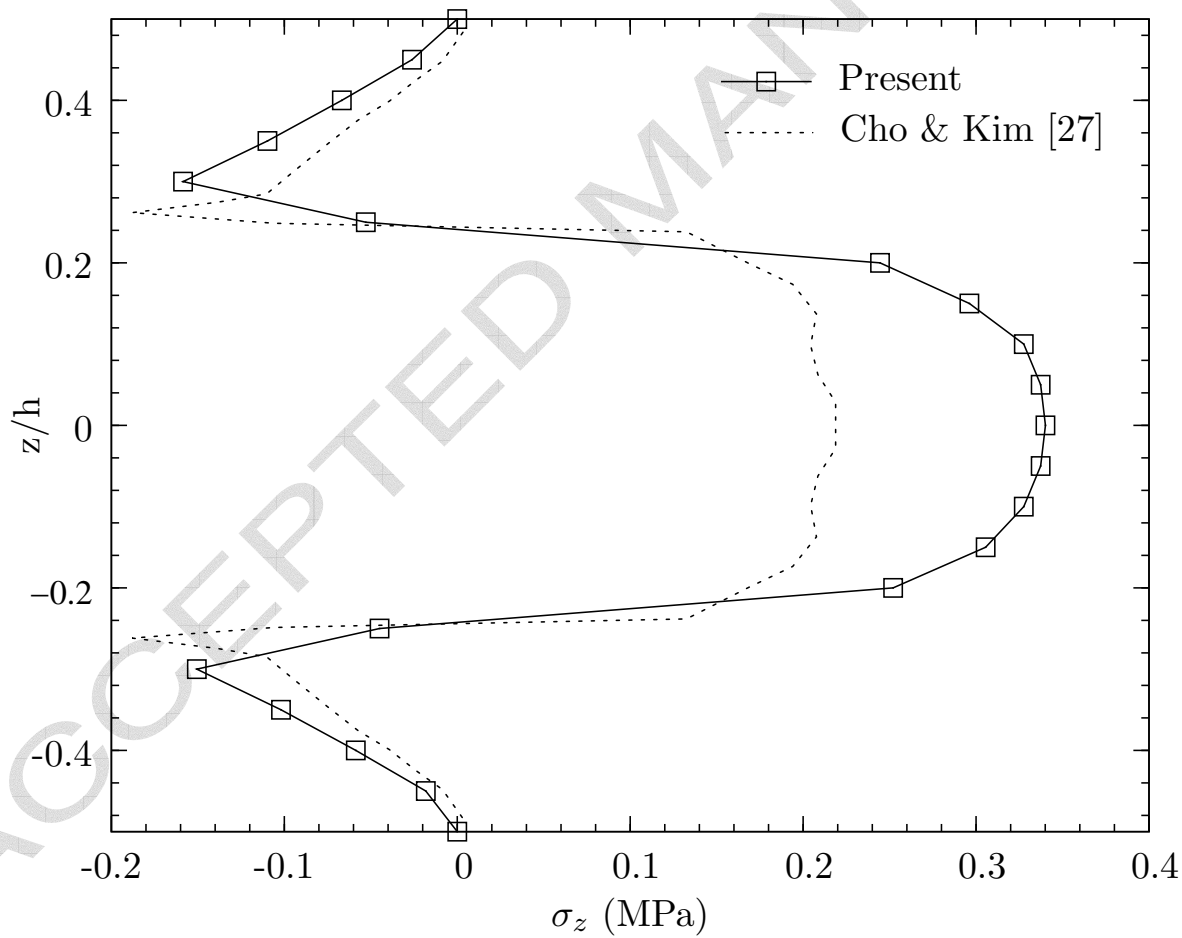

Fig. 14. Distribution of normal stress $\sigma_{z}$ versus $z$ at the free edge of $\left[90^{\circ} / 0^{\circ}\right]_{s}$ laminate under $\Delta T=1^{\circ} \mathrm{C}$. 


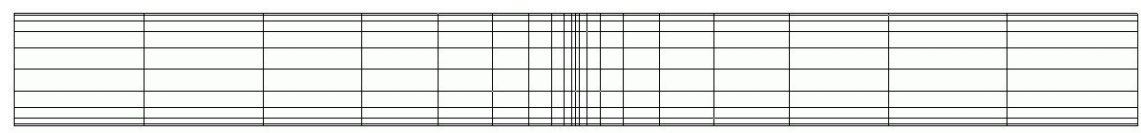

Fig. 15. typical mesh for the angle-ply laminate

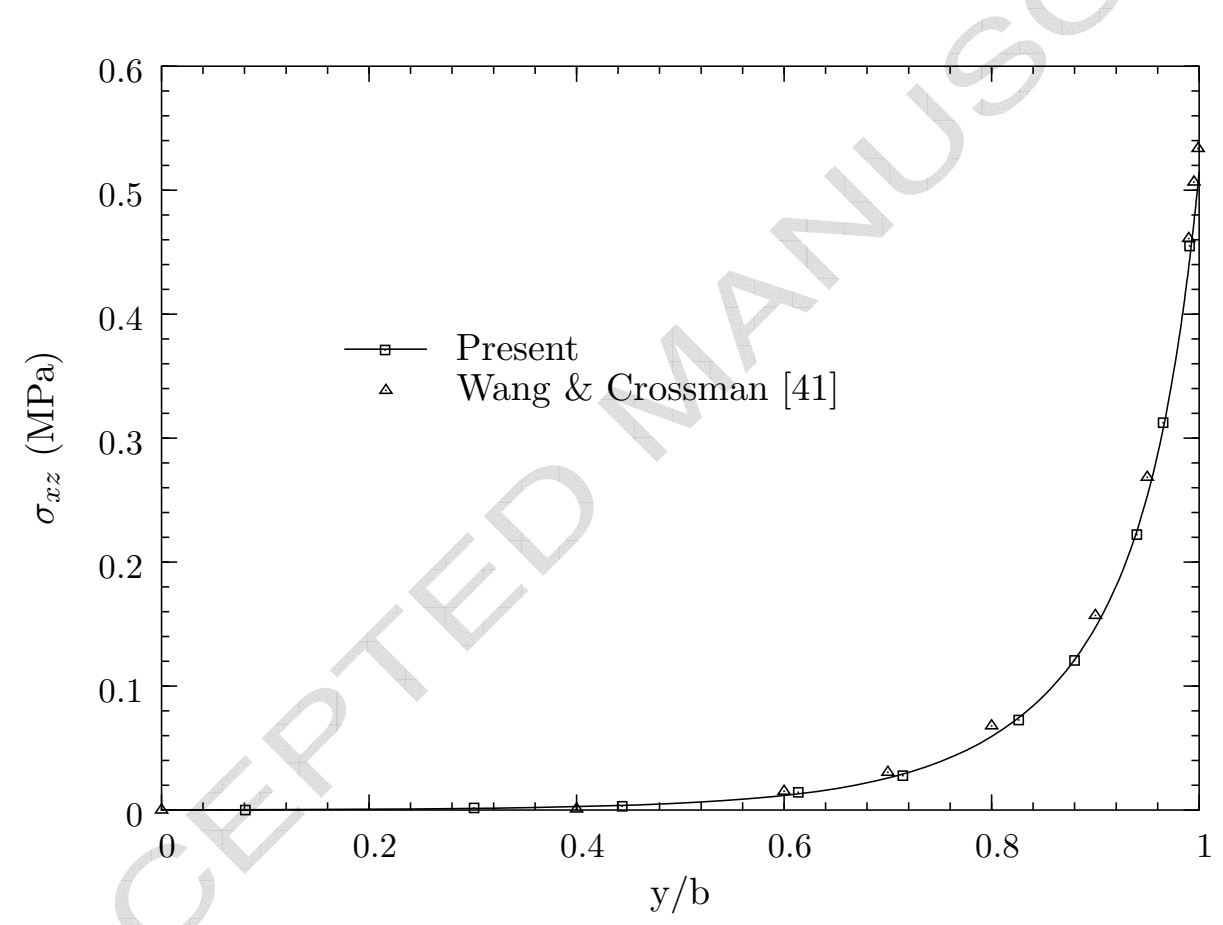

Fig. 16. Distribution of interlaminar shear stress $\sigma_{x z}$ along the $45^{\circ} /-45^{\circ}$ interface of $\left[45^{\circ} /-45^{\circ}\right]_{s}$ laminate under $\Delta T=1^{\circ} C$. 


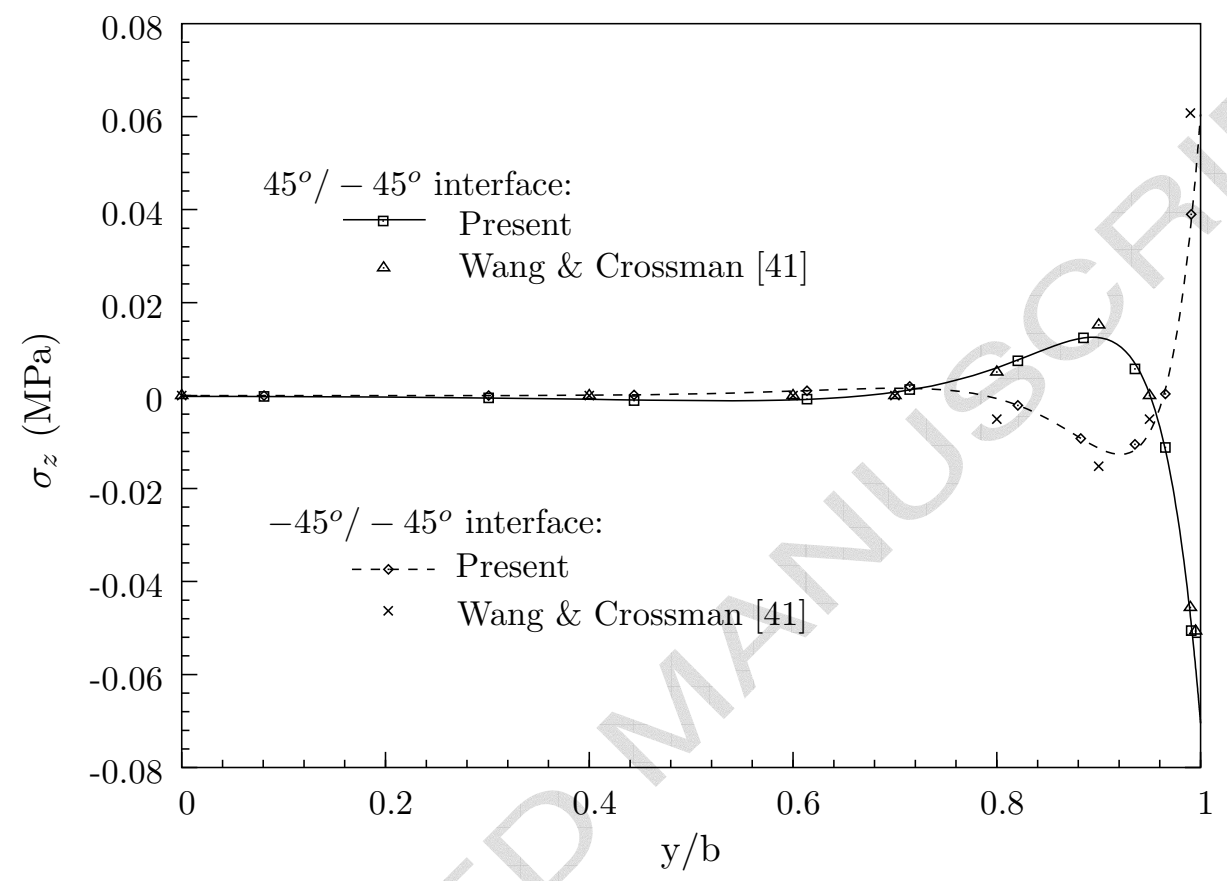

Fig. 17. Distribution of interlaminar normal stress $\sigma_{z}$ along the $45^{\circ} /-45^{\circ}$ and $-45^{\circ} /-45^{\circ}$ interfaces of $\left[45^{\circ} /-45^{\circ}\right]_{s}$ laminate under $\Delta T=1^{\circ} C$. 